\title{
Enhancement of Simvastatin ex vivo Permeation from Mucoadhesive Buccal Films Loaded with Dual Drug Release Carriers
}

This article was published in the following Dove Press journal: International Journal of Nanomedicine

\author{
Tarek A Ahmed (D) ${ }^{1,2}$ \\ Alaa O Bawazir ' \\ Waleed S Alharbi ${ }^{1}$ \\ Martin K Safo iD ${ }^{3}$ \\ 'Department of Pharmaceutics, Faculty of \\ Pharmacy, King Abdulaziz University, \\ Jeddah, Kingdom of Saudi Arabia; \\ ${ }^{2}$ Department of Pharmaceutics and \\ Industrial Pharmacy, Faculty of Pharmacy, \\ Al-Azhar University, Cairo, Egypt; \\ ${ }^{3}$ Department of Medicinal Chemistry and \\ the Institute for Structural Biology, Drug \\ Discovery and Development, School of \\ Pharmacy, Virginia Commonwealth \\ University, Richmond, VA 23298, USA
}

Correspondence: Tarek A Ahmed Department of Pharmaceutics, Faculty of Pharmacy, King Abdulaziz University, Jeddah 21589, Kingdom of Saudi Arabia Tel +96626400000 Ext 22250

Email tabdelnapy@kau.edu.sa
Background: Simvastatin (SMV), a hypocholesterolemic agent, suffers from very low bioavailability due to its poor aqueous solubility and extensive first-pass metabolism.

Methods: Two SMV carrier systems, namely, polymeric drug inclusion complex (IC) and mixed micelles (MM) nanoparticles, were developed and loaded into mucoadhesive buccal films to enhance SMV bioavailability. The two carrier systems were characterized and their permeation across human oral epithelial cells (OEC) was studied. The effect of IC to MM ratio $\left(\mathrm{X}_{1}\right)$ and the mucoadhesive polymer concentration $\left(\mathrm{X}_{2}\right)$ on the cumulative percent of drug released, elongation percent and the mucoadhesive strength, from the prepared mucoadhesive films, were optimized. Ex vivo permeation across bovine mucosal tissue was investigated. The permeation parameters for the in vitro and ex vivo release data were calculated. Results: Complexation of SMV with hydroxypropyl beta-cyclodextrin (HP $\beta$-CD) was superior to all other polymers as revealed by the equilibrium saturation solubility, stability constant, complexation efficiency and thermodynamic potential. SMV-HP $\beta$-CD IC was utilized to develop a saturated polymeric drug solution. Both carrier systems showed enhanced permeation across OEC when compared to pure drug. $\mathrm{X}_{1}$ and $\mathrm{X}_{2}$ were significantly affecting the characteristics of the prepared films. The optimized mucoadhesive buccal film formulation loaded with SMV IC and drug MM nanoparticles demonstrated superior ex vivo permeation when compared to the corresponding pure drug buccal film, and the calculated permeation parameters confirmed this finding.

Conclusion: Mucoadhesive buccal films containing SMV IC and drug MM can be used to improve drug bioavailability; however, additional pharmacokinetic and pharmacodynamic studies are required.

Keywords: simvastatin, inclusion complex, mixed micelles, optimization, buccal films

\section{Introduction}

Statins are indispensable for lowering the blood cholesterol levels and are increasingly being used to manage cardiovascular disorders; a major cause of death and morbidity around the world. ${ }^{1}$ Simvastatin (SMV), a member of statins, is widely used in the treatment of hypercholesterolemia and dyslipidemia. It is a prodrug that converts in the body into an active metabolite that competitively inhibits the activity of the enzyme hydroxymethylglutaryl-coenzyme A (HMG-CoA) Reductase. ${ }^{2}$ This enzyme catalyzes the conversion of HMG-CoA to mevalonic acid, and this results in inhibition of the endogenous production of cholesterol in the liver. SMV is a poorly water-soluble drug with a short half-life of $2 \mathrm{~h}$. It is 
commercially available as an oral tablet of different strength, such as 5,10, 20, 40 and $80 \mathrm{mg}$. Due to the intensive first-pass metabolism and the poor aqueous drug solubility $\left(6.3 \mu \mathrm{g} / \mathrm{mL}, \mathrm{pH} 1-7\right.$, at $\left.25^{\circ} \mathrm{C}\right)$ orally administered SMV tablets only result in about $5 \%$ bioavailability. ${ }^{3}$ Previous reports have mentioned an enhancement in SMV bioavailability upon complexation with different carriers such as polysaccharide arabinogalactan, ${ }^{4}$ development of caseinate-coated SMV-zein nanoparticles, ${ }^{5}$ preparation of drug nanosuspensions with Pluronic F127 and zirconium oxide ( $\mathrm{ZrO} 2)$ beads using a wet-milling technique, ${ }^{6}$ and development of SMV solid lipid nanoparticles. ${ }^{7}$

Progress in drug discovery and pharmaceutical technologies has been expanded dramatically in recent years. Reports indicated that around $40 \%$ of the newly discovered drugs are water insoluble and ineffective when administered to patients. ${ }^{8}$ Many of these drugs belong to class II of Biopharmaceutical Classification System (BCS) that are characterized by low solubility and high permeability. Solubility, dissolution and drug permeability are fundamental parameters that control the rate and extent of drug absorption and bioavailability. ${ }^{9}$ Different formulation strategies have been reported to improve the drug solubility and dissolution in order to achieve a suitable systemic drug concentration and a desired pharmacological effect. These strategies can be classified into physical, chemical and other miscellaneous modification techniques. ${ }^{10}$ Reduction in drug's particle size by micronization and nanosuspension formation, crystalline change by polymorph and amorphous/crystalline modifications, drug dispersion in hydrophilic carriers (solid dispersions), solid solutions and cryogenic methods are examples of physical modifications. ${ }^{11-15}$ Derivatization, salt formation and complexation are common types of chemical modifications. ${ }^{16,17}$ Cosolvency, hydrotropes, addition of surfactants and solubilizers, and supercritical fluid technology are good examples of other modifications. ${ }^{18-20}$ Among these strategies, inclusion complex has been emerged as a successful method for insertion of a hydrophobic drug molecule or the nonpolar part of one water-insoluble drug molecule (known as guest) into the cavity of a hydrophilic polymer (known as host). The most commonly used host polymers are cyclodextrins. $^{21,22}$ Moreover, surfactants have been utilized to improve the dissolution of poorly water-soluble drugs. When the concentration of the surfactant molecules exceeds their critical micelle concentration $(0.05-0.10 \%$ for most surfactants), micelle formation occurs. Hydrophobic drugs can be entrapped within the micelles core in a process called micellization which generally results in improving the drug solubility and more likely its bioavailability. ${ }^{23}$

Mucoadhesive buccal films are pharmaceutical dosage form that utilizes a water-dissolving polymer to allow the prepared films to quickly hydrate, adhere and dissolve when placed in the buccal, palatal, gingival, lingual, sublingual or cheek mucosa of the buccal cavity. ${ }^{24,25}$ They are promising drug delivery that release their drug content directly toward the buccal mucosa with subsequent drug absorption through the venous blood system that drains from the cheek. Accordingly, development of these films has the advantage of avoiding the extensive liver metabolism that are common with orally administered medications. $^{26}$ Mucoadhesion is the process of bonding of a synthetic or natural polymer(s) to the mucus membrane covering body tissue where wetting, adsorption and interpenetration of the employed biopolymer chains occur. $^{27}$ Polymers containing hydroxyl, carboxyl, amide, and amine groups can establish hydrogen bonds and promote adhesion to the mucosa. Localization of the mucoadhesive dosage forms on the buccal mucosa surface with subsequent release of their drug content result in improving the drug bioavailability by avoiding the hepatic firstpass effect. This finding has been previously mentioned for mucoadhesive buccal films loaded with different active pharmaceutical agents. ${ }^{28,29}$ Common examples for the mucoadhesive polymers are; cellulose derivatives (carboxymethyl cellulose and hydroxypropyl methyl cellulose), polyacrylic acid derivatives (Carbomers), poly(methacrylate) polymers (Eudragit), thiolated polymers (thiolated Chitosan and thiolated polyacrylic acid derivatives), chitosan, gelatin, hyaluronic acid, carrageenan, pectin and sodium alginate. ${ }^{25,30}$

In this study, SMV-hydroxypropyl beta-cyclodextrin (HP $\beta$-CD) inclusion complex (IC) and drug-loaded mixed micelle (MM) nanoparticles were developed and characterized as two different drug carrier systems. Permeation of both carriers across the human oral epithelial cells (OEC) was examined. SMV loaded IC and MM were incorporated into different mucoadhesive buccal film formulations to enhance the drug permeation across the buccal route through two different permeation mechanisms. The ratio of MM to IC and the percent of the mucoadhesive polymer were optimized for their effect on the cumulative drug released, elongation ratio, and mucoadhesive strength from the prepared SMV loaded mucoadhesive buccal films. Ex vivo permeation across bovine buccal mucosal tissue was studied. Permeation 
parameters for the in vitro and ex vivo data were calculated.

\section{Materials}

Simvastatin (SMV) was kindly supplied from the Saudi Arabian Japanese Pharmaceuticals Co. Ltd (SAJA) (Jeddah, KSA). Methanol, poloxamer 407 (pluronic F127), hydroxypropyl beta-cyclodextrin (HP $\beta$-CD), propylene glycol, citral, dialysis tubing cellulose membrane with an average flat width of $4.318 \mathrm{~cm}$ and molecular weight cut-off of 14,000 Da, sodium deoxycholate, polyethylene glycol (PEG 4000 and 6000) were all supplied from Sigma-Aldrich Inc. (St. Louis, MO, USA). Polyvinyl pyrrolidone (PVP) with a molecular weight of 44,000 Da (PVP K30) and 360,000 Da (PVP K90) were obtained from Spectrum Chemicals \& Laboratory Products (New Brunswick, NJ, USA). Polyvinyl pyrrolidone vinyl acetate (PVP VA64) was purchased from Shanghai Yuking Water Soluble Material Tech Co., Ltd. (Shanghai, China). Hydroxypropyl methylcellulose (HPMC), molecular weight of $86,000 \mathrm{Da}$, viscosity $4000 \mathrm{cp}$ ( $2 \%$ solution) and Carbomer (Carbopol) 940 were procured from Acros Organics (Morris Plains, New Jersey, USA). Soybean phosphatidylcholine was obtained from Lipoid $\mathrm{GmbH}$ (Ludwigshafen, Germany). Beta-cyclodextrin ( $\beta-C D)$ was a kind gift from Nihon Shokuhin Kako Co., Ltd. (Toyo, Japan). Mucin powder was supplied from Xian Kono Chem Co., Ltd (Xi'an, China). All other chemicals and solvents were of analytical grade.

\section{Methods}

\section{Preparation and Characterization of SMV Binary System}

\section{Selection of the Polymer}

The purpose of this section is to select the most appropriate polymer that is capable of enhancing the drug aqueous solubility. Eight different hydrophilic polymers were selected to develop drug binary systems. Selection of the polymers was based on their ability to develop either an inclusion complex or a solid dispersion. PEG 4000, PEG 6000, PVP K30, PVP K 90, poloxamer 407 (pluronic F127) and PVP VA64 were used to prepare solid dispersions in a drug to polymer ratios of 1:1, 1:2, and 1:4 (w/w). Drug inclusion complexes were also prepared utilizing $\beta-\mathrm{CD}$ and $\mathrm{HP} \beta-\mathrm{CD}$ in a drug to polymer molar ratios of $1: 1$ and 1:2. Kneading method was the technique utilized to develop the drug-polymer binary systems. Briefly, a specified weight of SMV was thoroughly mixed with the calculated amount of the studied polymer in a porcelain mortar and a diluted methanol/water solution $(50 \% \mathrm{v} / \mathrm{v})$ was added dropwise with continuous mixing until slurries were formed. The prepared slurries were then kept in an oven at $40^{\circ} \mathrm{C}$, for $48 \mathrm{~h}$, until dried mixtures were obtained. The dried drug-polymer binary systems were finally grounded to fine powders, sieved through a 60 mesh sieve and stored in a desiccator for further analysis.

\section{Equilibrium Saturation Solubility Study}

Excess amount of either pure SMV or the prepared binary systems was added to $10 \mathrm{~mL}$ distilled water in a screw cap glass vial. The prepared vials were placed in a thermostatically controlled shaking water bath (Model 1031; GLF Corp; Burgwedel, Germany), at $25 \pm 0.5^{\circ} \mathrm{C}$ for $72 \mathrm{hrs}$. Aliquots were withdrawn, filtered and assayed for drug content spectrophotometrically, using Jenway 6715 (Stone, UK), at $239 \mathrm{~nm}$ after 48 and $72 \mathrm{hrs,} \mathrm{respectively} \mathrm{to}$ ensure reaching drug-saturated solubility. Each experiment was performed in triplicate.

\section{Phase Solubility Study}

Based on the equilibrium saturation solubility study, HP $\beta$ CD was selected since this polymer showed the highest improvement in SMV solubility. Phase solubility study was carried out, according to Higuchi and Connors method, ${ }^{31}$ to investigate the type of interaction between SMV and HP $\beta$-CD. An excess amount of SMV was added into glass vials containing $10 \mathrm{~mL}$ of aqueous HP $\beta$ CD solutions $(2-20 \mathrm{mM})$. The vials were kept in a shaking water bath at a constant temperature of $25^{\circ} \mathrm{C}$ for $72 \mathrm{hrs}$. Samples $(n=3)$ from each vial were removed, filtered, and analyzed for SMV content spectrophotometrically at 239 nm. Phase-solubility plot was constructed and the stability constant (Ks) was calculated using the following equations:

$$
\text { Stability Constant }(K s)=\frac{\text { Slope }}{S_{\mathrm{o}}(1-\text { Slope })}
$$

where $S_{\mathrm{o}}$ is the equilibrium aqueous saturation solubility of SMV in the absence of HP $\beta-C D$ (obtained from the intercept of phase solubility plot).

The complexation efficacy (CE), which gives information about the studied polymer solubilizing efficiency for SMV, was also calculated according to the following equation:

$$
\text { Complexation Efficacy }(C E)=\frac{\text { Slope }}{1-\text { Slope }}
$$

The energy for transfer of SMV solubilization from pure water to aqueous solution of HP $\beta-C D$ was calculated as 
Gibbs free energy of transfer $\left(\Delta \mathrm{G}^{\circ}{ }_{\mathrm{tr}}\right)$. It refers to the thermodynamic potential that is minimized when a system reaches chemical equilibrium from an initial state to a final state at constant pressure and temperature. It was estimated by applying the following equation:

$$
\begin{aligned}
& \text { Gibbs free energy of transfer }\left(\Delta G^{\circ} t r\right) \\
& \quad=-2.303 R T \log \left(\frac{S c}{S_{\circ}}\right)
\end{aligned}
$$

where (Sc/So) is the ratio of the molar drug solubility in aqueous solution of HP $\beta$-CD to that in distilled water in absence of CD. $\mathrm{R}$ is the gas rate constant $\left(8.314 \mathrm{~J} /{ }^{\circ} \mathrm{C}\right) . \mathrm{T}$ is the temperature in Kelvin at which the study was conducted.

\section{Development of Saturated Polymeric SMV Solution (I st Carrier System)}

To prepare a saturated HP $\beta$-CD drug solution, different polymeric solutions containing $20,30,40$, and $50 \mathrm{mM}$ of HP $\beta$-CD were prepared by dissolving the calculated amount of the polymer in $50 \%$ (v/v) hydro-alcoholic solution. Known excess of SMV was gradually added to each solution over a magnetic stirrer. The prepared solutions were left stirring overnight at $40{ }^{\circ} \mathrm{C}$ to ensure complete evaporation of methanol that was ensured by measuring the volume of the aqueous liquid remained. Supernatants were decanted, filtered and assayed for SMV content spectrophotometrically at $239 \mathrm{~nm}$.

A saturated HP $\beta$-CD solution of $40 \mathrm{mM}$ polymer was prepared in $50 \%$ methanol/water solution over a magnetic stirrer and a known weight of SMV was subsequently added under a continuous stirring. The resulting polymeric drug solution was kept stirring overnight at $40^{\circ} \mathrm{C}$. Finally, the supernatant was separated and filtered to obtain the required saturated polymeric drug solution.

Known volume of the prepared saturated HP $\beta-C D$ drug solution was subjected to lyophilization. The solution was kept in a freezer at $-80^{\circ} \mathrm{C}$ for 24 hours, and finally it was subjected to freeze-drying for 48 hours using Christ Alpha 1-2 LD Plus lyophilizer (Martin Christ Gefriertrocknungsanlagen $\mathrm{GmbH}$, Osterode am Harz, Germany).

\section{Physicochemical Characterization of the Prepared Inclusion Complex Differential Scanning Calorimetry (DSC)}

The DSC thermograms of pure SMV, HP $\beta$-CD, SMV-HP $\beta$-CD physical mixture (1:1 ratio) and freeze-dried SMV-
HP $\beta-C D$ inclusion complex were investigated using the DSC apparatus of Shimadzu DSC TA-50 ESI (Tokyo, Japan). An aluminum crucible containing $5 \mathrm{mg}$ of the studied sample was examined under a dynamic N2 atmosphere at a heat flow rate of $10^{\circ} \mathrm{C} / \mathrm{min}$ in a temperature range of $20-300{ }^{\circ} \mathrm{C}$.

\section{Fourier Transform Infrared Spectroscopy (FTIR)}

The FTIR spectra of the same samples used in the DSC study were recorded between 4000 and $400 \mathrm{~cm}^{-1}$ using Nicolet iS10, Thermo Fisher Scientific (Waltham, MA).

\section{X-Ray Powder Diffraction (XRPD)}

To evaluate the crystallinity of pure SMV and freeze-dried SMV-HP $\beta$-CD inclusion complex, XRPD study was conducted. The diffraction patterns of both samples were recorded using a D/max 2500, Rigaku, powder X-ray diffractometer (Tokyo, Japan) at a scan speed of $0.5 \% \mathrm{~min}$.

\section{Development of SMV Mixed Micelles Nanoparticles (2nd Carrier System)}

SMV loaded mixed micellar system was prepared as previously reported using phosphatidylcholine (PC) and sodium deoxycholate (SDC) in a ratio of (1:0.8) with a total PC/SDC of $54 \mathrm{mg} / \mathrm{mL}^{32}$ The calculated amounts of PC, SDC and SMV were dissolved in the least quantity of absolute methanol. The organic solvent (methanol) was evaporated in a rotary evaporator at steady water bath temperature of $40{ }^{\circ} \mathrm{C}$ under a vacuum pressure using Buchi Rotavapor R-200 Buchi labortechink AG, CH9230 (Flawil, Switzerland). The dried thin layer obtained was then rehydrated with distilled water and kept shaking in the rotavapor for 30 minutes and finally sonicated for 15 minutes using ultrasonicator of Sonics Vibra cell, VCX 750; Sonics \& Materials, Inc. (Newtown, CT, USA). The obtained medicated mixed micelles (MM) nanoparticles were subjected to centrifugation at $25,200 \mathrm{~g}$ for $5 \mathrm{~min}$ at $4^{\circ} \mathrm{C}$ using (Sigma Laboratory centrifuge, 3K 30, Ostrode, Germany) in order to separate the unloaded drug. The supernatant containing the medicated micellar system was kept in the refrigerator at $4{ }^{\circ} \mathrm{C}$ until further analysis.

\section{Characterization of the Prepared SMV MM Nanoparticles Entrapment Efficiency}

Known volume of the prepared micellar solution was diluted, in a ratio of $1: 10 \mathrm{v} / \mathrm{v}$, with pure ethanol and SMV content was determined spectrophotometrically at 
$239 \mathrm{~nm}$. The entrapment efficiency (EE) was calculated according to the following equation:

$$
\begin{aligned}
\mathrm{EE}= & \frac{\text { Calculated amount of SMV in the micellar system }}{\text { Amount of SMV intially added }} \\
& \times 100
\end{aligned}
$$

\section{Morphological Study}

Surface morphology of the prepared micellar system was observed using transmission electron microscope (TEM) Model JEM-1230, JOEL (Tokyo, Japan). Briefly, few drops of the prepared MM nanoparticles solution were mounted on a carbon-coated grid and left for $5 \mathrm{~min}$ to allow for better adsorption on the carbon film. Excess liquid was removed by means of a filter paper. Finally, few drops of $1 \%$ phosphotungstic acid were added and the sample was examined.

\section{Particle Size Distribution and Zeta Potential Measurement}

Determination of particle size, zeta potential and polydispersity index for the prepared MM nanoparticle were performed using Malvern Zetasizer Nano ZS, Malvern Instruments (Malvern, UK).

\section{Permeability Study}

This section aimed to investigate the ability of both carrier systems to penetrate the cell membrane of the oral cell tissue. Human oral epithelial cells (OEC), Applied Biological Materials Inc. (Richmond, BC, Canada) were cultured and seeded $\left(1 \times 10^{6}\right.$ viable cells $)$ on T25 flasks. The culture medium was replaced daily. The cells suitability for the experiment was tested by examining their viability and confluence using the inverted light microscope (Carl Zeiss AG, Oberkochen, Germany).

The OEC was divided into three groups. The first group was exposed to $0.1 \mathrm{mg} / \mathrm{mL} \mathrm{SMV} \mathrm{in} \mathrm{the} \mathrm{form} \mathrm{of} \mathrm{inclusion}$ complex dispersion in dimethyl sulfoxide (DMSO) of $0.1 \%$. The second group was treated with the same drug concentration in the form of MM nanoparticles. The third group was subjected to the same concentration of pure SMV in DMSO. Blank OEC containing only the culture medium without drug was used as a reference. The experiment was conducted in triplicate. The OEC was incubated under standard conditions at $37^{\circ} \mathrm{C}$ in a humidified atmosphere containing $5 \% \mathrm{CO}_{2}$. The studied cells were collected at predetermined specified times and washed twice with ice-cold phosphate buffer saline. The collected cell pellets were suspended in $1 \mathrm{~mL}$ hypotonic saline solution $(0.3 \%)$ to allow cell swelling. Cell pellets suspensions were subjected to three repeated cycles of freezing in $-80{ }^{\circ} \mathrm{C}$ freezer for about 15 minutes and thawing at room temperature for 15 minutes. The cells were subsequently exposed to ultrasonic homogenization for $10 \mathrm{~min}-$ utes, using Sonics Vibra cell, VCX 750 Ultrasonic probe sonicator (Sonics and Materials Inc., Newton, CT, USA) at an output of $250 \mathrm{~W}$ and a frequency of $40 \mathrm{kHz}$, to ensure complete rupture of the cells. Finally, cell lysates were subjected to centrifugation at $15,000 \times \mathrm{g}$ for 60 minutes at $4^{\circ} \mathrm{C}$ using 3K30 sigma laboratory centrifuge (Osterode am Harz, Germany). The supernatant was collected, filtered and the concentration of SMV was calculated using highperformance liquid chromatography (HPLC) method., ${ }^{7,33}$ Agilent 1200 HPLC system of Agilent Technologies, Palo Alto (CA, USA) equipped with a UV diode array detector was used. The chromatographic analysis was performed using methanol- $0.05 \mathrm{M}$ potassium dihydrogen orthophosphate $(\mathrm{pH} \mathrm{5)}(80 / 20 \mathrm{v} / \mathrm{v})$ as a mobile phase. The flow rate was adjusted at $1.2 \mathrm{~mL} / \mathrm{min}$ and the absorbance was detected at $239 \mathrm{~nm}$. SMV retention time was detected at $9.7 \mathrm{~min}$. Drug standards containing known weight of SMV in the OEC were prepared, treated as mentioned above and assayed for drug content before determination of the unknown SMV concentrations in the tested samples.

\section{Development of SMV Mucoadhesive Buccal Films Experimental Design}

A response surface, 3-level factorial design, was used as a statistical tool to explore the effect of MM nanoparticles to inclusion complex ratio $\left(\mathrm{X}_{1}\right)$ and the carbopol percent $\left(\mathrm{X}_{2}\right)$ on the cumulative percent of drug release $\left(\mathrm{Y}_{1}\right)$, elongation percent $\left(\mathrm{Y}_{2}\right)$ and mucoadhesive strength $\left(\mathrm{Y}_{3}\right)$ from SMV-mucoadhesive buccal films. StatGraphics Centurion XV version 15.2.05 software, StatPoint Technologies, Inc. (Warrenton, VA, USA) was used to generate formulations and to statistically analyze the obtained results. A ratio of 1:2-2:1 and a concentration of $0-10 \%(\mathrm{w} /$ v) were used for $X_{1}$ and $X_{2}$, respectively. The goal was to maximize $Y_{1}-Y_{3}$. A total of 9 experimental runs were obtained and their composition are shown in Table 1.

\section{Preparation of the SMV-Mucoadhesive Buccal Film Formulations}

Different SMV mucoadhesive buccal films were prepared using different ratios of $X_{1}$ and various concentrations of $\mathrm{X}_{2}$ utilizing the solvent casting technique. Briefly, known 
Table I Experimental Runs and the Observed Values for Simvastatin Mucoadhesive Buccal Films Obtained from the Three-Level Factorial Design

\begin{tabular}{|c|c|c|c|c|c|c|c|c|}
\hline \multirow[t]{2}{*}{ Run } & \multirow[t]{2}{*}{$X_{\text {I (Ratio) }}$} & \multirow[t]{2}{*}{$X_{2}(\%)$} & \multicolumn{2}{|l|}{$Y_{1}(\%)$} & \multicolumn{2}{|l|}{$\mathbf{Y}_{2}(\%)$} & \multicolumn{2}{|c|}{$\mathbf{Y}_{3}$ (Newton) } \\
\hline & & & Observed & Predicted & Observed & Predicted & Observed & Predicted \\
\hline FI & $\mathrm{I}: 2$ & 10 & 64.91 & 66.15 & 20.0 & 17.22 & 804.0 & 793.27 \\
\hline F2 & I:I & 10 & 72.7 & 72.92 & 25.0 & 31.38 & 715.0 & 771.44 \\
\hline $\mathbf{F 3}$ & I:I & 0 & 91.4 & 92.72 & 150.0 & 126.38 & 218.0 & 191.77 \\
\hline F4 & $2: 1$ & 5 & 85.8 & 89.28 & 100.0 & 92.22 & 583.0 & 633.11 \\
\hline F5 & $2: 1$ & 0 & 101.2 & 101.78 & 150.0 & 161.38 & 220.0 & 215.61 \\
\hline F6 & $\mathrm{I}: 2$ & 0 & 86.7 & 87.39 & 80.0 & 92.22 & 250.0 & 280.61 \\
\hline F7 & $2: 1$ & 10 & 84.9 & 83.43 & 50.0 & 46.38 & 908.0 & 862.27 \\
\hline F8 & I:I & 5 & 81.03 & 79.49 & 50.0 & 67.22 & 606.0 & 575.77 \\
\hline F9 & $\mathrm{I}: 2$ & 5 & 75.4 & 73.45 & 52.5 & 43.05 & 651.0 & 631.11 \\
\hline
\end{tabular}

Abbreviations: $X_{1}$, mixed micelle to inclusion complex ratio; $X_{2}$, percent of carbopol; $Y_{1}$, cumulative percent of drug released; $Y_{2}$, elongation percent; $Y_{3}$, mucoadhesive strength.

volumes of the prepared MM nanoparticles and polymeric drug inclusion complex were mixed and completed to $50 \mathrm{~mL}$ with distilled water. The penetration enhancer (citral) and the plasticizer (propylene glycol) were subsequently added to the above mixture, in a concentration of $2 \%$ each, and the mixture was thoroughly mixed over a magnetic stirrer. HPMC $(1 \% \mathrm{w} / \mathrm{v})$, as a film-forming agent, and the specified concentration of carbopol 940, as a mucoadhesive polymer, were eventually added. The obtained mixtures were left overnight in a refrigerator to allow complete swelling of the polymers and formation of a clear solution. The prepared SMV polymeric solutions were poured into $9 \mathrm{~cm}$ diameter glass petri dishes, about $64 \mathrm{~cm}^{2}$ dish area, and kept in an oven at $40{ }^{\circ} \mathrm{C}$ until complete drying. A drug load equivalent to $688 \mu \mathrm{g}$ for each buccal film that has diameter of $1.5 \mathrm{~cm}\left(1.76 \mathrm{~cm}^{2}\right.$ area) was considered. Finally, the prepared films were stored in a sealed desiccator until further characterization.

\section{Characterization of the Prepared SMV Buccal Films Content Uniformity}

To ensure good distribution of SMV in the prepared mucoadhesive buccal films, the content uniformity was evaluated. Three films, of $1.76 \mathrm{~cm}^{2}$ area, from each formulation were immersed into 50-mL hydro-alcoholic solutions (50:50) in a $100 \mathrm{~mL}$ glass bottles. The bottles were incubated in a shaking water bath at $25^{\circ} \mathrm{C}$ for 48 h. Aliquots from each bottles were withdrawn, filtered using $0.45 \mu \mathrm{m}$ syringe filter and analyzed for SMV content using UV-Vis spectrophotometer at $\lambda \max$ of $238 \mathrm{~nm}$. The average reading of three films was considered and compared to the theoretical drug load.

\section{Thickness}

Digital micrometer of Mitutoyo Co. (Kawasaki, Japan) was utilized to determine the average thickness of 10 individual reading from each formulation.

\section{Percent Elongation}

To measure the stretch of a film strip sample when a stress is applied, strain or the elongation percent is measured. ${ }^{34}$ An elongation testing apparatus that has been designed in our laboratory was used for the measurement as previously published in our work. ${ }^{11,35,36}$ A rectangular film strips (1× $4 \mathrm{~cm}$ ), from each formulation, were placed between two jaws separated by $2 \mathrm{~cm}$. The upper jaw is fixed in position while the lower one is freely moving and is attached to a definite weight. The change in the strip length after a time of five minutes was measured. The experiment was done in triplicate for each film. The percent elongation was calculated utilizing the following equation:

$$
\begin{aligned}
\text { Elongation }(\%)= & \frac{\begin{array}{l}
\text { The final length } \\
\text { of the film }
\end{array}-\begin{array}{l}
\text { Initial lenght } \\
\text { of the film }
\end{array}}{\begin{array}{l}
\text { Initial length } \\
\text { of the film }
\end{array}} \\
& \times 100 \quad \text { s. }
\end{aligned}
$$

\section{Evaluation of the Mucoadhesive Strength}

Mucoadhesion is a characteristic of a dosage form that can interact with mucosal membranes; especially with their mucin component. ${ }^{37}$ To evaluate this property for buccal films, the mucoadhesive strength is utilized to measure the 
force needed to detach the film from the buccal cavity. ${ }^{38}$ In this study, two techniques have been utilized to evaluate the mucoadhesive strength of the prepared buccal films namely, the tensile strength method ${ }^{38}$ and the mucin particle method. ${ }^{39}$ The aim was to compare and validate results obtained from both methods. The first method is based on measuring the interaction between the film and buccal tissue physically, while the second is based on evaluating the change in zeta potential produced upon interaction of the prepared film with mucin powder suspension. Results obtained for the mucoadhesive strength using the tensile strength apparatus method were used in the experimental design; while those obtained from the mucin particle method were used for comparison and validation purposes only.

\section{Evaluation of the Mucoadhesive Strength Using Tensile Strength}

In this experiment, the force required to break the interaction between the prepared film and the buccal mucosal tissue was used to assess the mucoadhesive strength. ${ }^{40}$ Cow buccal mucosal tissue, obtained from local slaughterhouse, was used as a model to evaluate the mucoadhesive properties for the prepared films using Shimadzu Tensile Strength Machine, EZ-SX with high-precision $( \pm 0.5 \%)$, Shimadzu Co. (Kyoto, Japan). Briefly, a buccal tissue of $2 \mathrm{~cm}^{2}$ was fixed on a glass slide attached to the apparatus lower stage (stationary platform). Samples from each films of the same surface area were adhered to another glass slide, using two-sided adhesive tape, that was attached to the apparatus upper platform. The film was allowed to interact with the mucosal tissue by applying downward force for 2 minutes before running the experiment. The crosshead was then raised at a constant speed of $0.5 \mathrm{~mm} /$ min and the force required for complete detachment (break point) was recorded. Each experiment was repeated three times.

Evaluation of the Mucoadhesive Strength Using Mucin Particle Method

A simple method that depends on measuring the zeta potential of a mucin powder suspension before and after incubation with a known weight of the studied films for $48 \mathrm{~h}$ was used. ${ }^{7,39,41}$ Briefly, a mucin powder suspension $(0.1 \mathrm{mg} / \mathrm{mL})$ was prepared by adding the calculated amount of bovine mucin into a $100 \mathrm{mM}$ acetate buffer solution and mixed overnight to ensure complete dispersion. A known weight (45 mg) from each film was dipped into a test tube filled with $3 \mathrm{~mL}$ of the prepared mucin suspension and the mixture was kept in a shaking water bath for $48 \mathrm{~h}$. Zeta potentials of the prepared mixture and the mucin powder suspension were finally measured using Malvern Zetasizer Nano ZS, Malvern Panalytical Ltd Instruments (Malvern, UK).

Results obtained for both methods (tensile strength and mucin particle method) were compared to validate the second method and authenticate a simple reliable method for determination of bioadhesiveness.

\section{In vitro Release Study}

The release of SMV from the prepared medicated buccal films was investigated using an automated Franz diffusion cell apparatus of Hanson research, Microette Plus (Chatsworth, CA, USA) over a period of $6 \mathrm{~h}$. The apparatus is adapted with $1.76 \mathrm{~cm}^{2}$ diffusion area and a receptor chamber of $7 \mathrm{~mL}$ volume. Synthetic cellulose membrane of Sigma-Aldrich Inc., molecular weight cut-off $=14,000$ $\mathrm{Da}$, was used as a diffusion membrane. Buffer solution of $\mathrm{pH} 6.2$, to simulate the buccal saliva, containing $0.5 \%$ sodium lauryl sulphate was used as a diffusion medium. Buccal films of $1.76 \mathrm{~cm}^{2}$ were placed in the receiver chamber above the diffusion membrane. Aliquots were withdrawn automatically and analyzed by HPLC as previously described. Each buccal film formulation was studied in triplicate.

\section{Experimental Design Statistical Analysis and Optimum Desirability}

The statistical significance for the relationship between the independent $\left(\mathrm{X}_{1}\right.$ and $\left.\mathrm{X}_{2}\right)$ and dependent variables $\left(\mathrm{Y}_{1}, \mathrm{Y}_{2}\right.$ and $\mathrm{Y}_{3}$ ) was identified after introduction of the obtained results into the response column of the Statgraphics Plus ${ }^{\circledR}$ software. Data were considered significant at p-value $<0.05$. The optimum desirability was estimated and the optimized formulation that achieves the study goal was proposed.

\section{Preparation and Characterization of the Optimized SMV Buccal Film}

The proposed optimized SMV loaded buccal mucoadhesive film formulation was prepared, characterized for the cumulative drug release $\left(\mathrm{Y}_{1}\right)$, elongation percent $\left(\mathrm{Y}_{2}\right)$ and mucoadhesive strength $\left(\mathrm{Y}_{3}\right)$ as previously mentioned. The obtained results (observed values) were compared to the predicted ones and the residual was calculated. 


\section{In vitro Dissolution Time}

The time needed for complete dissolution of the optimized buccal film was assessed according to the method previously published by Vila et al. ${ }^{25}$ A small film strip of $1 \times 2 \mathrm{~cm}(\mathrm{n}=3)$ was added to $25 \mathrm{~mL}$ of ultrapure distilled water maintained at $37{ }^{\circ} \mathrm{C}$ in a $50-\mathrm{mL}$ beaker that was kept under magnetic stirring with vortex formation. The elapsed time until the film strip was totally dissolved was recorded.

\section{Ex vivo Release Study}

A fresh cow buccal mucosal tissue was used to evaluate SMV release from the optimized mucoadhesive buccal film formulation loaded with either a pure drug or the studied SMV carriers (MM nanoparticles and polymeric drug inclusion complex). Cow buccal mucosa, without any treatment, was freshly obtained from a local slaughterhouse immediately after the animal was killed and stored on ice until it was transferred to our laboratory. The study was conducted according to the same procedure described in the in vitro permeation section except that the cow buccal tissue was used to replace the artificial cellulose membrane.

\section{Permeation Parameters of SMV \\ Mucoadhesive Buccal Films Release Data}

The in vitro and ex vivo permeation profiles of SMV, from the prepared buccal films, were constructed. The steady flux $\left(J_{S S}\right)$ was estimated from the slope of the gradient portion of the linear curve obtained by plotting the cumulative SMV permeated per unit area against time. SMV permeability coefficient $(\mathrm{P})$ was calculated using the equation: $\mathrm{P}=J_{s S} / \mathrm{C}_{0}$. Where $\mathrm{C}_{0}$ is the initial SMV concentration in the donor compartment. SMV diffusion coefficient (D) was determined by representing the cumulative amount of drug permeated against the square root of time and applying the following equation: $\mathrm{D}=\left(\text { slope } / \mathrm{C}_{\mathrm{o}}\right)^{2} * \pi$. The permeation parameters for the optimized and pure drugloaded formulations were also calculated.

\section{Results and Discussion SMV Binary Systems}

SMV is considered as a poorly water-soluble drug. ${ }^{42}$ The obtained results for the aqueous solubility of pure SMV, at $25{ }^{\circ} \mathrm{C}$, revealed an average solubility value of $10.692 \pm$ $0.0153 \mu \mathrm{g} / \mathrm{mL}$ as indicated in Figure 1. Screening of the studied polymers was performed to select the one that is capable of preparing a drug binary system characterized by enhanced drug aqueous solubility. Kneading was the technique employed to prepare the binary systems. The equilibrium saturation solubility and phase solubility study have been performed to deduce the solubility efficiencies of the prepared binary systems.

Two types of binary systems, inclusion complex and solid dispersion, were investigated utilizing eight different hydrophilic polymers at different drug to polymer ratios. The solubility of SMV in these binary systems is illustrated in Figure 1. Results of the equilibrium saturation solubility illustrated superiority of HP $\beta$-CD over all the studied polymers. An improvement in SMV aqueous solubility by more than 11 folds, when compared to the solubility of pure SMV, was obtained with HP $\beta-C D$ at 1:2 drug to polymer ratio. This effect could be attributed to an efficient drug entrapment in the hydrophilic cyclodextrin cavity, enhancement in the wettability of SMV's particles, and to the change in the drug crystallinity from crystalline to amorphous state. This finding is in a good agreement with Zhang and his coworkers who studied the influence of HP $\beta$-CD complexation on the aqueous solubility and bioavailability of toltrazuril. ${ }^{43}$ Parmar and his colleagues also reported similar finding for the effect of HP $\beta-C D$ on lamotrigine. ${ }^{44}$ They attributed the improvement of lamotrigine bioavailability and dissolution characteristics to the complete entrapment of the drug inside the cyclodextrin cavity and to the change in drug crystallinity. Similar finding was also mentioned for the enhancement of aripiprazole dissolution after preparing a drug cyclodextrin binary systems. $^{21}$

Phase solubility study was performed to investigate the interaction of SMV with HP $\beta$-CD. Results obtained are graphically represented in Figure 2. It was noticed that the solubility of SMV was improved upon increasing the molar concentration of HP $\beta$-CD. The equation that best describes the relationship was found to be; $Y=0.3877 X-0.6842$. The obtained regression coefficient (R2) was 0.9934 , which indicates an excellent correlation. The calculated stability constant $(\mathrm{Ks})$ and the complexation efficacy $\left(\mathrm{C}_{\mathrm{E}}\right)$ were found to be $0.3228 \mathrm{M}^{-1}$ and 3.4523 , respectively. According to Higuchi and Connors classification, ${ }^{31}$ two types of complexation are most likely to occur; type A and type B. The former occurs when the solubility of the drug is increased upon increasing the polymer concentration. The latter is obtained when the solubility of the drug is increased with increasing the polymer concentration up to a certain limit followed by a plateau. ${ }^{14}$ The former (type A) may be further classified into $A_{L}$ and $A_{P}$ types. When the 
140

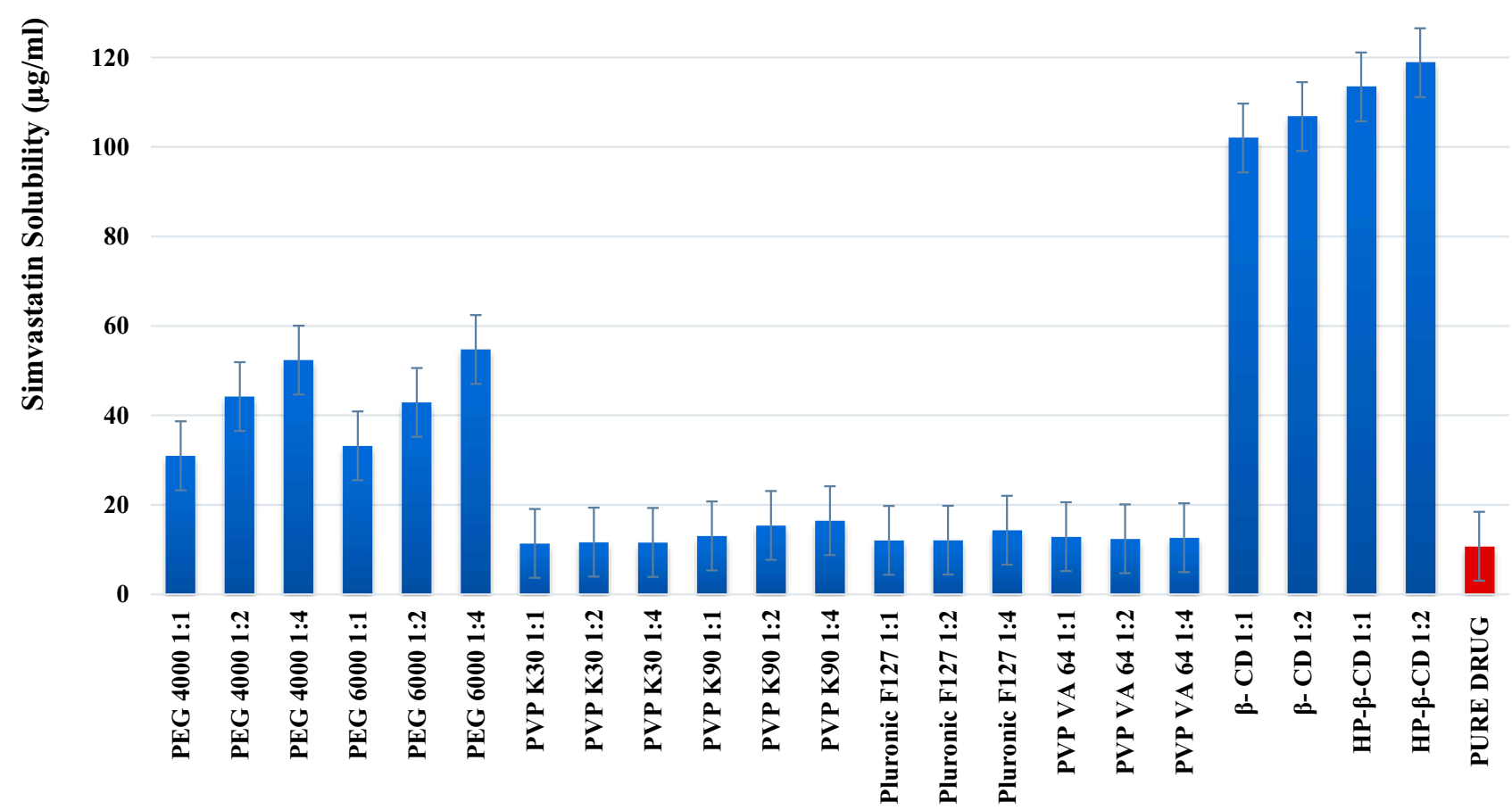

\section{Types and ratio of the studied polymers}

Figure I Solubility of simvastatin in the studied polymers using different drugs to polymer ratios.

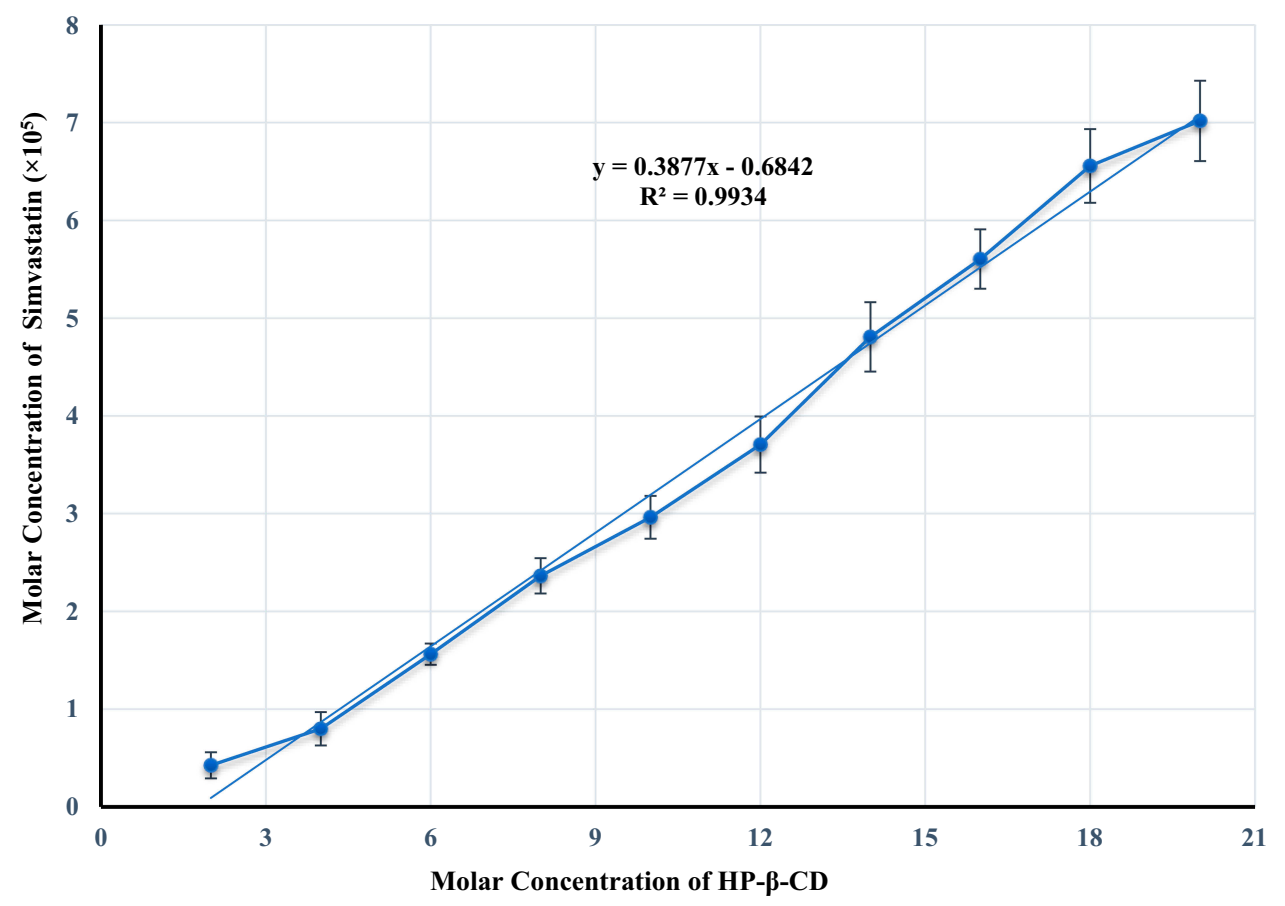

Figure 2 Phase-solubility study of simvastatin in aqueous solution of hydroxypropyl-beta-cyclodextrin. 
drug solubility is increased upon increasing the concentration of the polymer, and the complex formed is first order with respect to the polymer and first or higher order with respect to the drug, type $A_{L}$ is formed. If the complex obtained is first order with respect to the drug, but second or higher order with respect to the polymer, then $A_{P}$ type complexation is obtained. According to the data obtained, graphically illustrated in Figure 2, an $\mathrm{A}_{\mathrm{L}}$ type of complexation between HP $\beta-C D$ and SMV was formed since SMV solubility was increased upon increasing the concentration of the polymer and the complex formed was first order with respect to HP $\beta$-CD and first or higher order with respect to SMV. Our results are in a good agreement with Mura et al, who studied the solubilizing competency and complexation tendency of HP $\beta$-CD toward flufenamic acid in the buccal cavity environment and reported an $A_{L}$ type of complexation. ${ }^{45}$ The phase solubility study of acyclovir with HP $\beta$-CD showed the same outcome; a linear increase in the solubility of acyclovir was noticed upon increasing the HP $\beta$-CD concentration. ${ }^{46}$ The interesting similarity of the phase solubility study results of HP $\beta$-CD with different drugs may be attributed to the capability of this polymer to incorporate the studied drug into the polymer cavity with an efficiency of complexation stability produced. Thus, HP $\beta$ $\mathrm{CD}$ could be considered as a polymer of choice for many poorly soluble drugs utilizing the inclusion complexation technique.

To evaluate the process of SMV solubilization in an aqueous media of HP $\beta$-CD at different concentrations, Gibbs free energy of transfer $\left(\Delta \mathrm{Gtr}^{\circ}\right)$ was calculated to indicate whether the process is appropriate or not. ${ }^{14,47,48}$ Results for $\Delta \mathrm{Gtr}^{\circ}$ of SMV in an aqueous solution of HP $\beta-\mathrm{CD}$ at $25^{\circ} \mathrm{C}$ indicated marked change from -1261.35 to $-8214.49(\mathrm{~J} / \mathrm{mol})$ when the HP $\beta$-CD molar concentration was increased from 2 to $20 \mathrm{mM}$. The obtained negative values indicated spontaneous thermodynamic reaction between SMV and HP $\beta-C D$ molecules in the aqueous medium. Moreover, the decrease in the negativity of $\Delta \mathrm{G}_{\mathrm{tr}}{ }^{\circ}$ means that the system reactions become more favorable as the carrier concentration increased. This behavior could be attributed to the increase in van der Waals, electrostatic and hydrogen bonding upon increasing the cyclodextrin concentrations.

\section{Development of Saturated Polymeric SMV Solution (I st Carrier System)}

Cyclodextrins are a family of cyclic oligosaccharides that create a 3-dimensional toroid structure, providing a cavity that can accommodate hydrophobic molecules. ${ }^{49}$ It has been reported that complexation with cyclodextrins is used to improve the solubility and enhance the bioavailability of a wide varieties of active pharmaceutical agents such as lamotrigine, ${ }^{44}$ toltrazuril, ${ }^{43}$ aripiprazole, ${ }^{21}$ dexamethasone, ${ }^{50}$ niclosamide, ${ }^{51}$ clozapine, ${ }^{52}$ and others.

Upon examining the drug solubility in the polymeric solutions containing an increasing amount of HP $\beta$-CD in the range of $20-50 \mathrm{mM}$, the drug solubility was increased linearly until reaching $40 \mathrm{mM}$ polymeric solution. The solubility of SMV in $40 \mathrm{mM}$ polymeric solution was increased by more than 114 folds $(1229.73 \mu \mathrm{g} / \mathrm{mL})$ when compared to the aqueous solubility of pure SMV (10.69 $\mu \mathrm{g} / \mathrm{mL}$ ). No further increase in the drug solubility was noticed when the molar ratio of the polymer was increased to $50 \mathrm{mM}$.

A saturated polymeric drug solution was prepared utilizing the inclusion complex of SMV and HP $\beta-C D$ at 40 $\mathrm{mM}$ polymer solution. Selection of this concentration of the HP $\beta$-CD solution was also based on the stability of the polymeric drug complex prepared which affect the efficiency of complexation and full entrapment of the drug molecules in the polymer cavity. This finding was also noticed, in our previously published work, with glimepiride in aqueous polymeric solution of polyvinyl pyrrolidones and we attributed this effect to the improvement in drug wettability. ${ }^{53}$

\section{Physicochemical Characterization of SMV- HP $\beta-C D$ IC}

The physiochemical properties of pure SMV and HP $\beta$-CD were studied using DSC, FTIR and XRPD in order to assess the characteristics of both components in their physical mixture and in the prepared freeze-dried inclusion complex.

Differential scanning calorimetry (DSC) is a validated tool for studying the thermodynamic changes and the interactions that occur between tested components. $^{54}$ The DSC thermographs of pure SMV, HP $\beta-C D$, their physical mixture and the freeze-dried inclusion complex are illustrated in Figure 3. The thermogram of pure SMV revealed a sharp endothermic peak at $141.35{ }^{\circ} \mathrm{C}$ indicating the crystallinity of the drug, while the thermogram of HP $\beta-C D$ showed a short broad endothermic peak between $50^{\circ} \mathrm{C}$ and $110^{\circ} \mathrm{C}$. The physical mixture of the two components, SMV and HP $\beta-C D$, illustrated distinctive peaks 


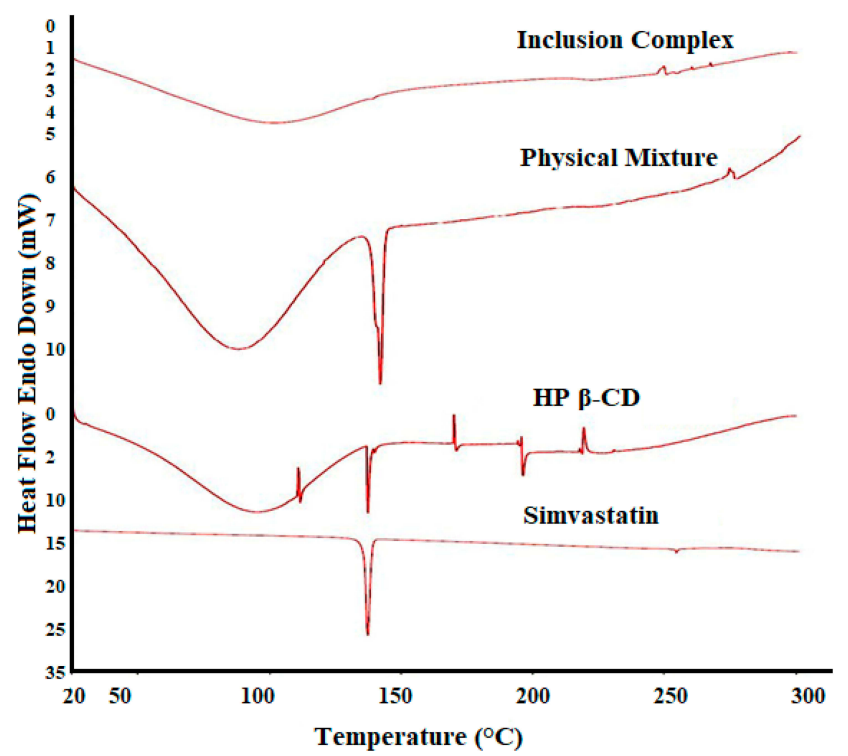

Figure 3 Differential scanning calorimetry thermograms of pure simvastatin, hydroxypropyl-beta-cyclodextrin, physical mixture and inclusion complex.

corresponding to each component which indicates lack of interference and absence of any possible interaction upon physical mixing of the two components. This behavior was previously mentioned for paclitaxel/ Dimethyl- $\beta$-CD physical mixture. ${ }^{55}$ The thermogram of the freeze-dried inclusion complex revealed absence of the drug melting endothermic peak and the presence of the HP $\beta$-CD's broad peak. This finding confirms a drug-polymer complexation and inclusion of the drug inside the HP $\beta-C D$ cavity. Choi et al, reported similar finding for paclitaxel during development of drug (2,6-di-O-methyl)-b-cyclodextrin inclusion complex. They mentioned absence of the drug endothermic peak and attributed this behavior to the molecular encapsulation of paclitaxel within the (2,6-di-O-methyl)-b-cyclodextrin cavity. ${ }^{55}$

FTIR spectroscopy is another physicochemical characterization technique that measures how much light from a beam containing many frequencies is absorbed by the sample. A spectrum of the signal at a series of discrete wavelengths is obtained and used as a fingerprint of the sample. FTIR has been widely used to assess the characteristics of cyclodextrins. ${ }^{56}$ Change in the intensity of the stretching vibration, absence, or shift in bands locations can be correlated with complexation. ${ }^{48,54}$ The FTIR spectra of pure SMV, HP $\beta$-CD, their physical mixture, and the freeze-dried inclusion complex are illustrated in Figure 4. Pure SMV showed a distinct peak at $3545 \mathrm{~cm}^{-1}$ corresponding to the hydroxyl $(\mathrm{O}-\mathrm{H})$ stretching vibration. The
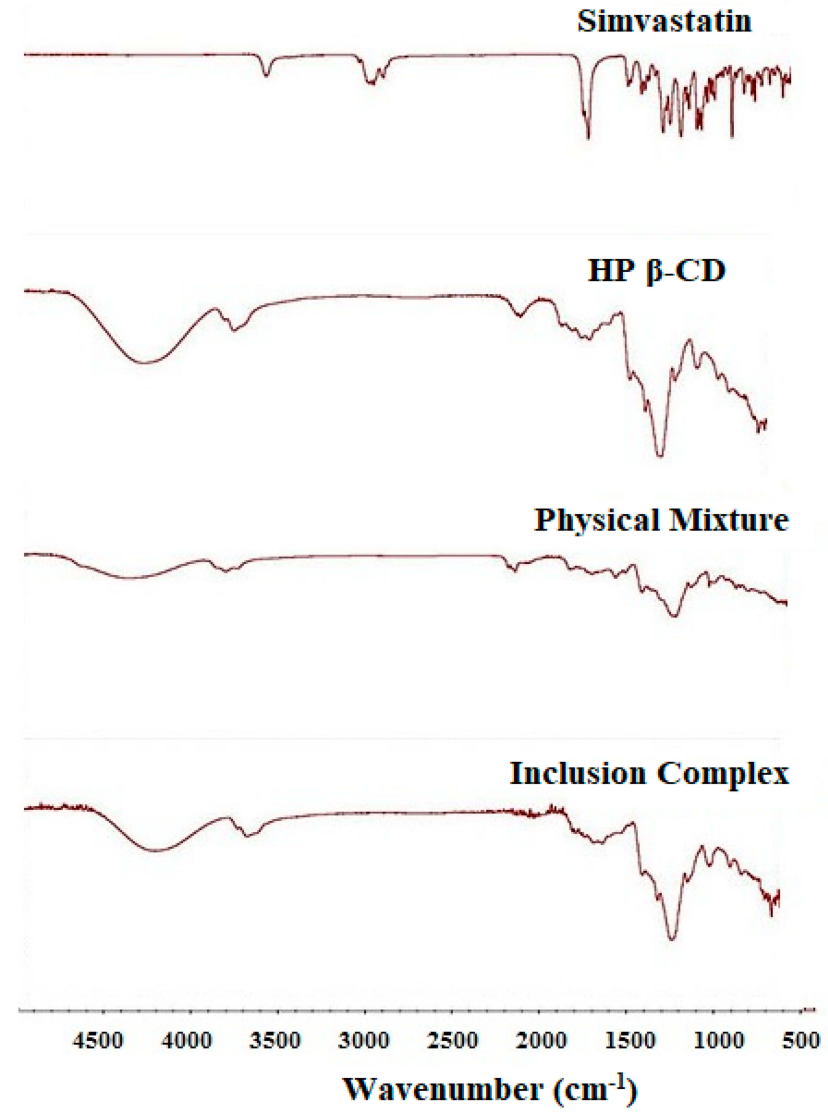

Figure 4 Fourier transform infrared spectrum of pure simvastatin hydroxypropylbeta-cyclodextrin, physical mixture and inclusion complex.

alkene $(\mathrm{C}-\mathrm{H})$ stretching vibrations were observed at $3010 \mathrm{~cm}^{-1}$ and $2810 \mathrm{~cm}^{-1}$. Another characteristic peak for the lactone functional group $(-\mathrm{C}-\mathrm{O})$ was observed at $1700 \mathrm{~cm}^{-1}$. SMV carbonyl $(-\mathrm{C}=\mathrm{O})$ groups were detected at $1164 \mathrm{~cm}^{-1}$ and $1066 \mathrm{~cm}^{-1.7,57}$ The FTIR spectra of HP $\beta$-CD demonstrated a prominent band at $3600 \mathrm{~cm}^{-1}$ due to hydroxyl $(\mathrm{O}-\mathrm{H})$ group stretching vibration. Bands in the range of 1384-1460 cm ${ }^{-1}$ corresponding to $\mathrm{CH}_{2}$ and $\mathrm{CH}_{3}$ bending vibrations were observed. Other bands at $1142 \mathrm{~cm}^{-1}$ and $972 \mathrm{~cm}^{-1}$ for $(\mathrm{C}-\mathrm{H})$ and $(\mathrm{C}-\mathrm{O})$ stretching vibrations, respectively were also noticed. ${ }^{58}$ The spectra of the physical mixture showed a slight overlapping and a small reduction in the intensity of HP $\beta-C D$ peaks, which indicate that a partial complexation might have occurred through weak interaction. In contrast, SMV vibrational peaks were mostly absent in the spectra of the inclusion complex. This finding indicates that the drug $(\mathrm{O}-\mathrm{H})$ and $(-\mathrm{C}-\mathrm{O})$ groups interacted with the HP $\beta$ $\mathrm{CD}$ side chain. Moreover, the two distinct peaks of HP $\beta$ $\mathrm{CD}$ namely $(\mathrm{O}-\mathrm{H})$ and $(\mathrm{C}-\mathrm{H}, \mathrm{C}-\mathrm{O})$ stretching vibrations 
did not shift and still located at their locations during complex formation which confirmed the stability of the inclusion complex formed.

$\mathrm{X}$-ray powder diffraction (XRPD) is a technique used to assess the crystallinity of a pure drug or its physically modified (inclusion complex) components in the solid state. ${ }^{56}$ It has been used as another supporting tool that identifies the formation of drug inclusion complex. The change in the intensity of diffraction peaks or shifting in their locations might confirm complex formation. ${ }^{54}$ The freeze-dried inclusion complex was utilized in this type of analysis. XRPD of pure SMV illustrated several intense diffraction peaks of the crystalline drug structure as shown in Figure 5. XRPD pattern of the prepared drug inclusion complex revealed a flat diffraction pattern with many peaks of low intensity, corresponding to an amorphous substance.

Based on the results of DCS, FTIR and XRPD, SMV might be hosted as a guest in the HP $\beta$-CD cavity in the amorphous form. This finding confirms inclusion complex formation and results in an enhancement in the drug aqueous solubility.

\section{Development and Characterization of SMV MM Nanoparticles (2nd Carrier System)}

SDC and PC are amphiphilic molecules that have the ability of self-assembly in aqueous solution just above the CMC. In this study, both substances were used to develop SMV loaded MM as a second drug nanocarrier system. Selection of both components was based on their tolerability and safety. ${ }^{32}$ Drug loaded SDC/PC MM nanoparticles have been reported to improve solubility of poorly soluble drugs such as curcumin, ${ }^{59}$ CucurbitacinB $^{32}$ and amphotericin B. ${ }^{60}$ Although SDC alone could be used to form micelles and to solubilize insoluble drugs, the solubilization ability of the micelles prepared using this component alone is far lower than that of bile salt/PC MM. ${ }^{59}$ During MM nanoparticles formation the hydrophobic part of bile salt, SDC, interacts with the PC acyl chain to form the micelle hydrophobic core while, the hydrophilic shell is in direct contact with water. This effect, to a certain extent, is dependent on the concentration of the bile salts as previously suggested by Mazer et al. ${ }^{61}$ Development of SMV loaded
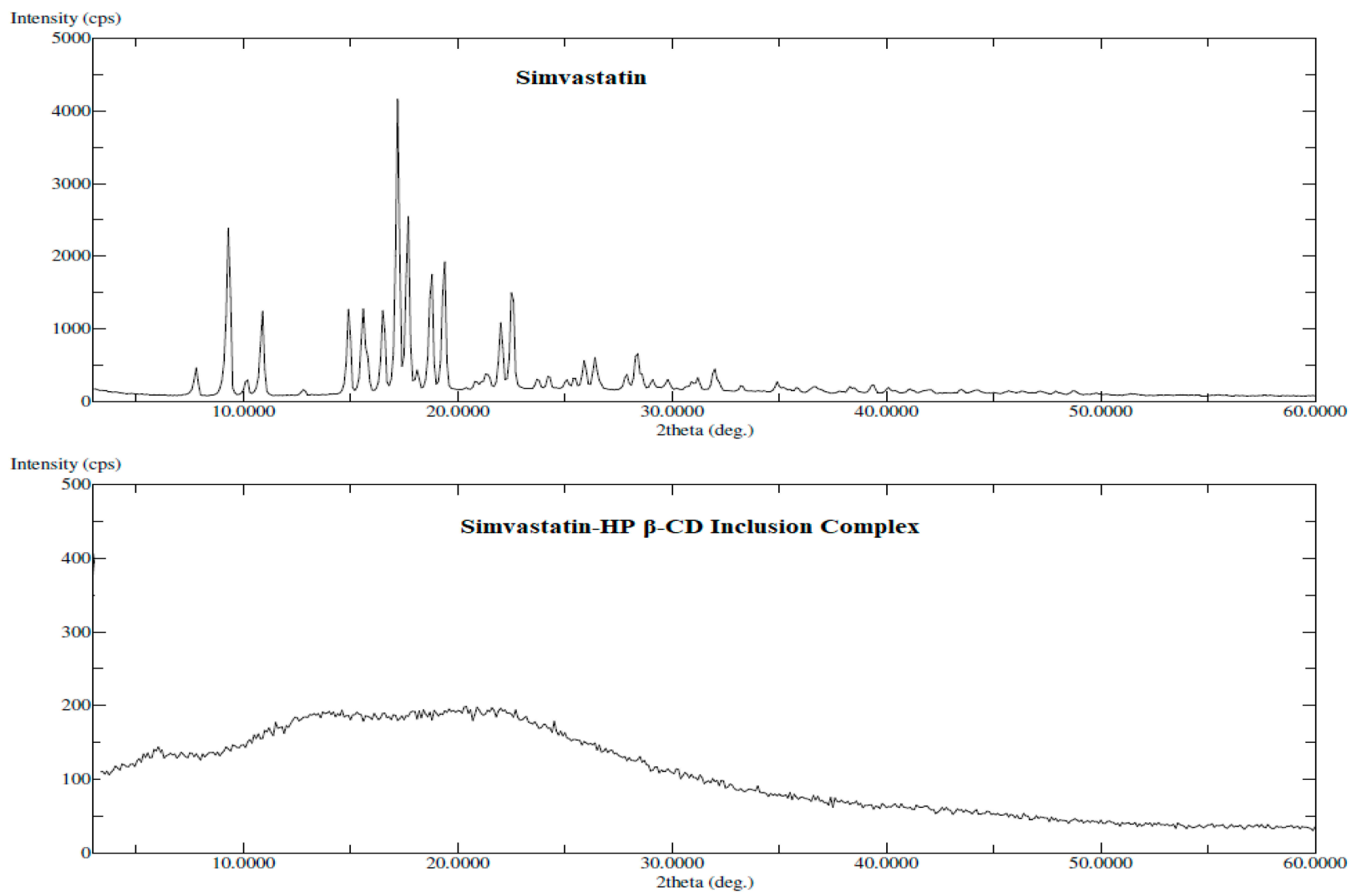

Figure 5 X-ray powder diffraction of pure simvastatin and inclusion complex. 
SDC/PC MM nanoparticles were achieved using the solvent evaporation technique, followed by centrifugation and separation of the drug-loaded MM particles.

The prepared MM nanoparticles system increased the aqueous solubility of SMV by more than 430 folds, ie, from $10.69 \mu \mathrm{g} / \mathrm{mL}$ to $4611.89 \mu \mathrm{g} / \mathrm{mL}$. The average EE (\%) was calculated as $54 \pm 0.88 \%$. The average zeta potential value for the prepared MM nanoparticles was $-30.81 \pm 2.12 \mathrm{mV}$. The negativity of the zeta potential is mainly attributed to the presence of the anionic surfactant, SDC, which surrounds the micelles, and attributed to formation of stable particles. It has been previously reported that when the surface electric charge (zeta potential value) is close to the critical value $( \pm 30 \mathrm{mV})$, mutually repulsion between particles occur, which keep the system stable. ${ }^{62}$ The mean particle size of the prepared MM nanoparticles was found to be $16.48 \pm 1.516$ $\mathrm{nm}$; which is in the nano-sized range (1 to 100 nanometers). The obtained value for PDI was $0.2157 \pm$ 0.081 , which indicates high homogeneity of the prepared particles. Morphological study of the MM nanoparticles formulation revealed formation of spherical nanoparticles without aggregation as illustrated in Figure 6. It has been suggested that MM illustrate spherical-shaped nanoparticles with the phospholipid bilayer in the center and bile salts surrounding the perimeter of micelles, which is referred to as "mixed disk model" formulation. ${ }^{63}$ It is expected that our formulation exhibits the same behavior; the soybean phosphatidylcholine molecules are in the center, and sodium deoxycholate molecules surrounding the perimeter, while SMV is dissolved in the MM core as graphically illustrated in Figure 6.

\section{Permeability Study}

The ability of the prepared SMV carriers to permeate across the buccal mucosa was studied and compared to pure drug. Figure 7 illustrates the intracellular drug concentration after exposure the human oral epithelial cells (OEC) to $0.1 \mathrm{mg} /$ $\mathrm{mL}$ SMV. Based on the Biopharmaceutics Classification System, SMV is a class-II compound that is characterized by a poor aqueous solubility and an adequate permeability through biological membranes. ${ }^{64}$ Acceptable drug permeation was noticed from the pure drug. The inclusion complex and the MM nanoparticles formulations resulted in enhanced SMV permeation with superiority of the MM nanoparticles formulation. This superiority could be attributed to the nature of the components (Sodium deoxycholate and soybean phosphatidylcholine) which facilitate SMV transport across the cell membrane. Previous study has also indicated enhancement in the rate of vinpocetine permeation across the buccal oral epithelial cells from a drug complex, in the form of solid dispersion with polyvinyl pyrrolidone vinyl acetate, when compared to pure vinpocetine solution. ${ }^{14}$

\section{Development and Characterization of SMV Mucoadhesive Buccal Films}

Different SMV loaded buccal films were prepared using different ratios of MM nanoparticles to inclusion complex $\left(\mathrm{X}_{1}\right)$ and various percentage of carbopol $\left(\mathrm{X}_{2}\right)$ utilizing the solvent casting technique. HPMC was used as a filmforming substance while citral and propylene glycol were used as a penetration enhancer and a plasticizer, respectively. Plasticizer was used to overcome film brittleness and soften the rigidity of the film structure by reducing the

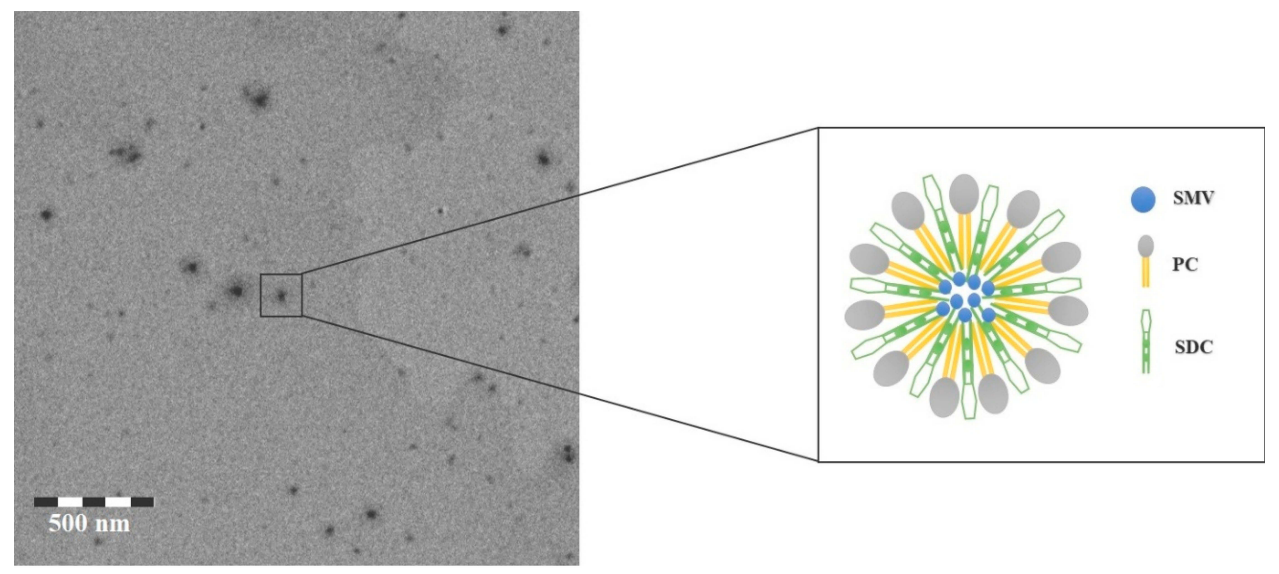

Figure 6 Transmission electron microscope image (left-side) and graphical representation (right-side) of simvastatin mixed micelles nanoparticles formulation. 


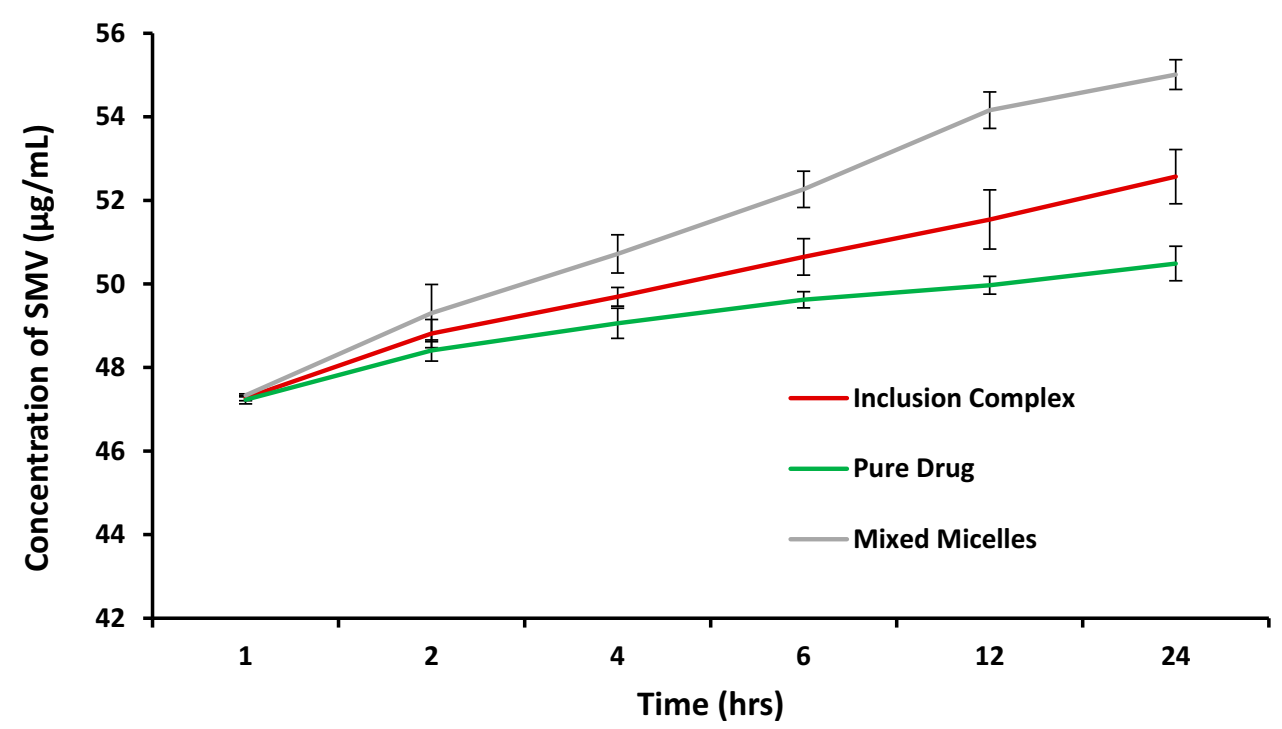

Figure 7 Simvastatin intracellular permeation across human oral epithelial cells following treatment with different drug formulations.

intermolecular forces. ${ }^{65}$ Carbopol 940 was included as a mucoadhesive polymer. The prepared films were characterized for content uniformity, thickness, percent elongation, mucoadhesive strength and in vitro drug release. The prepared films, of $1.76 \mathrm{~cm}^{2}$ area, showed a SMV content in the range of $711.81 \pm 32.82-664.29 \pm 35.60 \mu \mathrm{g}$ and a thickness of $0.266 \pm 0.052-0.126 \pm 0.091 \mathrm{~mm}$, with a percentage elongation ranging from $20 \pm 2.5$ to 150 $\pm 10 \%$. Mucoadhesive strength was in the range 218 \pm 17.95 to $908 \pm 69.91 \mathrm{~N}$, while results of the in vitro release study illustrated a cumulative percent drug release of $64.91 \pm 4.12$ to $101.2 \pm 8.28 \%$.

The obtained results for characterization of the prepared films indicate an adequate distribution of SMV carrier systems (inclusion complex and MM nanoparticles) and uniform distribution of HPMC and carbopol in the studied films as indicated from the values of film content and thickness.

Elongation percent is a character that measures the mechanical properties and the ability of the prepared films to withstand handling during manufacturing, distribution and administration. The type and percent of the filmforming polymer, amount of the plasticizer and the drug nature have a profound effect on the elongation percent of the prepared film. ${ }^{34}$ The ultimate film preparation should be elastic and soft enough to handle and show a satisfactory damage-resistance ability. ${ }^{66,67}$ In this work, the prepared films showed wide variation in the elongation percent. Incorporation of carbopol during film preparation resulted in increased viscosity and the formation of less elastic films.
Ahmed and El-Say previously illustrated the negative effect of increasing the polymer percentage on the elongation percent of finasteride loaded transdermal films. The authors attributed this behavior to the polymeric solution viscosity and brittleness of the prepared films, necessitating addition of more plasticizer. ${ }^{11}$

\section{Mucoadhesive Strength}

This test was performed to measure the ability of the prepared films to interact with the buccal epithelial cells; which in turn plays an important role in the formulation absorptivity and bioavailability. Carbopol has been verified for its efficacy as a mucoadhesive polymer in pharmaceutical researches. Hoffmann and Daniels evaluated the mucoadhesion of fast dissolving tablets containing carbopol and found that formulations containing carbopol showed more adhesion to mucosal surface up to three-fold compared to that without carbopol. ${ }^{68}$

Determination of the mucoadhesion strength for the prepared nine films was achieved utilizing two methods; tensile strength and mucin particle test. Results of the tensile strength method, illustrated in Table 1, were correlated to the zeta potential values obtained using the mucin particle test and used to validate this method.

In the tensile strength method, the force needed to detach the film from the biological membrane was determined. The mucoadhesion strength has been shown to be affected by hydrogen bond formation during the mucoadhesion interaction; the more hydrogen bond interaction the more elevated mucoadhesion strength produced. ${ }^{69}$ Formulations F1, F2 and 
F7 showed the highest detachment force, while formulations F3, F5, and F6 exhibited the lowest force. Formulations F4, F8, and F9 demonstrated intermediate force of detachment. These observations could be directly related to the concentration of carbopol. The carboxyl groups of carbopol is expected to form hydrogen bonding with the mucin amide group of the buccal mucosa. It can be deduced that formulations containing high quantity of carbopol exhibited more adhesion due to more hydrogen bond interaction. Further explanation will be provided in the upcoming paragraph.

The mucoadhesive properties of the films were also investigated using the mucin particle test by measuring the change in zeta potential of mucin suspension after incubation with the prepared films. Data obtained were correlated to the value of the mucoadhesive strength force in order to validate the mucin particle method. Mucin is a glycoprotein complex that has a negatively charged sugars, either sialic acid or O-sulfosaccharides. ${ }^{70}$ The carbohydrate content may account for up to $90 \%$ of the mucin weight. The polypeptide chains of mucin have domains rich in threonine and/or serine amino acids whose hydroxyl groups are in O-glycosidic linkage with oligosaccharides. The protein structure of mucin composed of two distinct regions namely; the amino- and the carboxy-ended regions that contain the amino acid cysteine which participates in the formation of disulfide linkages among and within the molecule. Previous report indicated that pure mucin powder suspension exhibits a negative zeta potential value due to ionization of the carboxyl group. ${ }^{39,71}$ In this work, the estimated value was found to be $-9.2 \mathrm{mV}$.

Anionic polymers, such as carbopols (Polyacrylic acid derivate), are believed to form hydrogen bonds between the polymer carboxylic groups and the mucin hydroxyl groups. $^{72}$ Ion-dipole (electrostatic) interactions may also occur between carbopols and mucin. ${ }^{73}$ Upon mixing the pure mucin powder suspension with the prepared films, the value of zeta potential has been shifted to $-14.1 \mathrm{mV}$ for formulations containing $5 \%$ carbopol and to $-19.3 \mathrm{mV}$ for formulation containing $10 \%$ carbopol. The change in the zeta potential value was proportional to the concentration of carbopol in the formulation. Higher carbopol concentration demonstrated marked zeta potential change. Accordingly, the mucin particle test is in a good agreement with the tensile strength method.

\section{In vitro Release}

The release of SMV from the prepared buccal films is illustrated in Figure 8. SMV exhibited a constant release profile from all the studied films. The drug release was highly affected by the MM to inclusion complex ratio and to the percent of carbopol. Formulations containing high ratio of inclusion complex and high percent of carbopol showed lower drug release rate. Formulation F5, containing 2:1 ratio of $\mathrm{MM}$ to inclusion complex and $0 \%$ of carbopol, demonstrated a drug release of $74.65 \pm 6.12 \%$ and $101.2 \pm$ $8.28 \%$ after 3 and $6 \mathrm{~h}$, respectively. In contrast, formulation $\mathrm{F} 1$, containing $\mathrm{MM}$ to inclusion complex ratio of $1: 2$ and a carbopol percent of $10 \%$, showed a percent drug release of $37.52 \pm 3.1 \%$ and $64.91 \pm 4.12 \%$, respectively. As previously discussed in the permeability study section, drug-loaded MM nanoparticles formulation was superior to the inclusion complex drug carrier. Accordingly, formulation containing high ratio of the former exhibited better release profile. The effect of carbopol concentration could be related to the viscosity of the formulation. When the concentration of carbopol was increased from zero to $10 \%$ the viscosity of the polymeric solution, used to develop the buccal films, was increased which leads to formation of a dense polymeric matrix film after evaporation of the solvent. This dense polymeric matrix film retards the drug release from the buccal film and so demonstrates controlled drug release profile and low cumulative percent of drug released.

\section{Optimization of the SMV Buccal Film Formulation}

A three-level experimental design was implemented to study the effect of two formulation variables affecting the cumulative percent of SMV released, the elongation percent and the mucoadhesive strength from drug-loaded buccal films. Table 1 illustrates the observed and predicted values for the studied responses.

Statistical analysis for the effect of $\mathrm{X}_{1}$ and $\mathrm{X}_{2}$ on $\mathrm{Y}_{1}, \mathrm{Y}_{2}$ and $\mathrm{Y}_{3}$ was carried out by multiple regression analysis and two-way ANOVA using the StatGraphics software. Values for the estimated effect of the studied factors, F-ratio, and the associated $P$-value are illustrated in Table 2. A positiveestimated value indicates a synergistic effect for a variable, while a negative value is an indication of an antagonistic effect. The value of the F-ratio compares the actual and expected variations in the variable averages; an F-ratio greater than 1 is a sign of a location effect, and thus the $P$-value reports the significance level. A factor is considered to significantly affect the studied response if the $P$-value differs from 0 and is less than 0.05 . The equations of the fit model were found to be: 

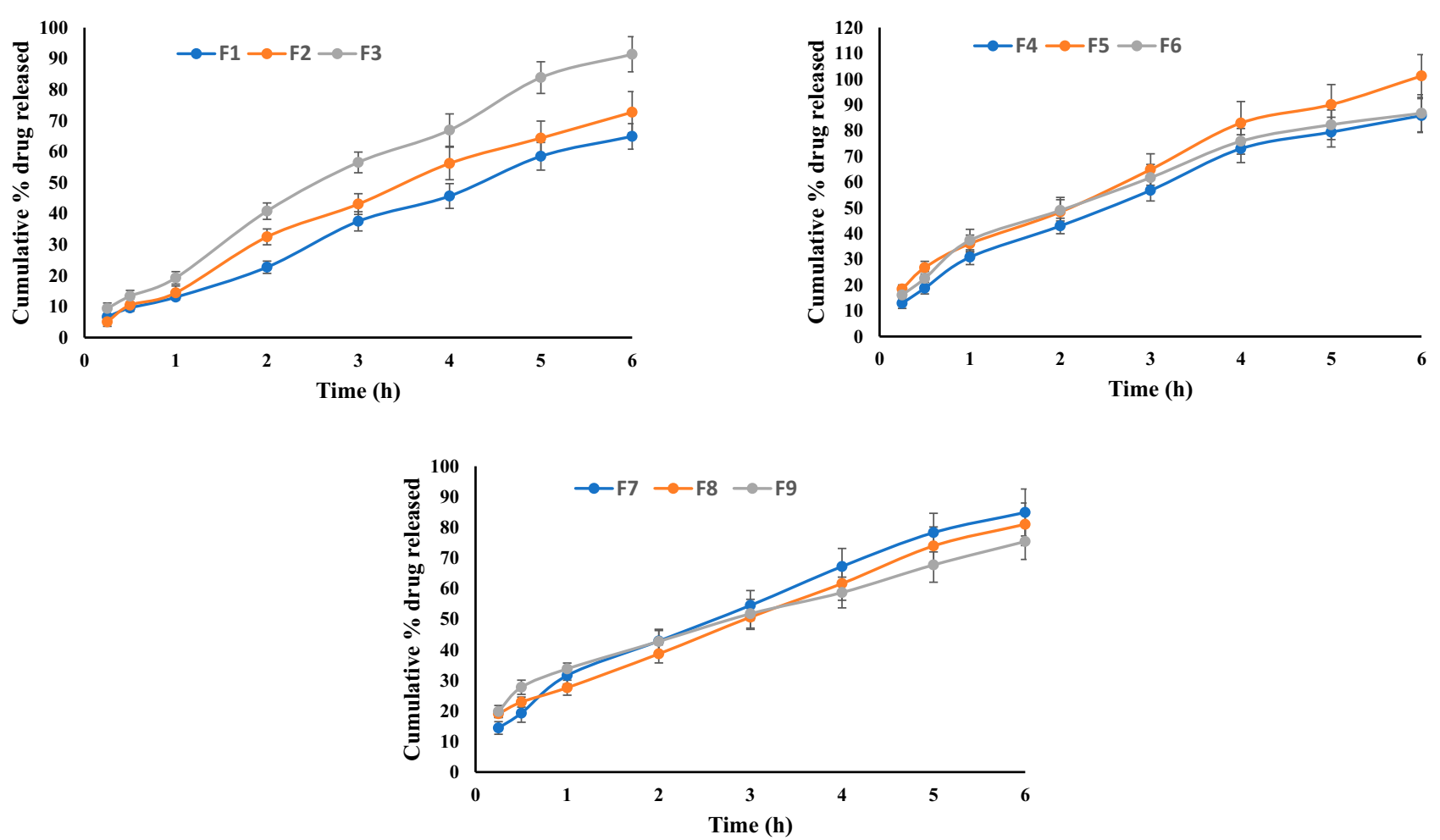

Figure 8 In vitro release of simvastatin from the prepared buccal films.

Table 2 Estimated Effects of Factors, F-Ratio, and Associated $p$-value for $Y_{1}-Y_{3}$ of SMV-Buccal Films Formulations

\begin{tabular}{|c|c|c|c|c|c|c|c|c|c|}
\hline \multirow[t]{2}{*}{ Factor } & \multicolumn{3}{|l|}{$\mathbf{Y}_{\mathbf{1}}$} & \multicolumn{3}{|l|}{$\mathbf{Y}_{2}$} & \multicolumn{3}{|l|}{$\mathbf{Y}_{3}$} \\
\hline & Estimated Effect & F-Ratio & p-value & Estimated Effect & F-Ratio & p-value & Estimated Effect & F-Ratio & p-value \\
\hline $\mathbf{x}_{1}$ & 14.96 & 52.58 & $0.0054 *$ & 49.17 & 8.09 & 0.0654 & 2.0 & 0.00 & 0.9701 \\
\hline$x_{2}$ & -18.93 & 84.16 & $0.0027^{*}$ & -95.0 & 30.21 & $0.0119 *$ & 579.67 & 139.29 & $0.0013^{*}$ \\
\hline $\mathbf{x}_{1} \mathbf{x}_{1}$ & 2.88 & 0.65 & 0.4788 & 0.83 & 0.00 & 0.9795 & 112.67 & 1.75 & 0.2772 \\
\hline $\mathbf{X}_{1} \mathbf{x}_{2}$ & 2.75 & 1.18 & 0.3569 & -20.0 & 0.89 & $0.4 \mid 45$ & 67.0 & 1.24 & 0.3466 \\
\hline$X_{2} X_{2}$ & 5.78 & 2.62 & 0.2041 & 23.33 & 0.61 & 0.4926 & -188.33 & 4.90 & 0.1137 \\
\hline $\mathbf{R}^{2}$ & \multicolumn{3}{|l|}{$97.91 \%$} & \multicolumn{3}{|l|}{$92.99 \%$} & \multicolumn{3}{|l|}{$98.00 \%$} \\
\hline Adj-R ${ }^{2}$ & \multicolumn{3}{|l|}{$94.45 \%$} & \multicolumn{3}{|l|}{$81.30 \%$} & \multicolumn{3}{|l|}{$94.67 \%$} \\
\hline SEE & \multicolumn{3}{|l|}{2.53} & \multicolumn{3}{|l|}{21.16} & \multicolumn{3}{|l|}{60.15} \\
\hline MAE & \multicolumn{3}{|l|}{1.29} & \multicolumn{3}{|l|}{10.49} & \multicolumn{3}{|l|}{30.48} \\
\hline
\end{tabular}

Notes: *Significant effect of factors on individual responses, $p$-value $<0.05$.

Abbreviations: $X_{1}$, mixed micelle to inclusion complex ratio; $X_{2}$, percent of carbopol; $X_{1} X_{1}, X_{1} X_{2}$, and $X_{2} X_{2}$ are the interaction terms between the factors; $Y_{1}$, cumulative percent of drug released; $Y_{2}$, elongation percent; $Y_{3}$, mucoadhesive strength; $R^{2}, R$-squared; Adj- $R^{2}$, adjusted R-squared; $S E E$, standard error of estimate; $M A E$, mean absolute error.

$$
\begin{aligned}
Y 1= & 86.7879-0.152569 \times X 1-3.87333 \times X 2 \\
& +0.00519104 \times X 1^{2}+0.0164716 \times X 1 \times X 2 \\
& +0.115667 \times X 2^{2} \\
Y 2= & 26.3696+1.92516 \times X 1-8.16547 \times X 2 \\
& +0.0015003 \times X 1^{2}-0.120012 \times X 1 \times X 2 \\
& +0.466667 \times X 2^{2} \\
&
\end{aligned}
$$$$
\begin{aligned}
Y 3= & 796.5-22.2363 \times X 1+75.5293 \times X 2+0.202841 \\
& \times X 1^{2}+0.40204 \times X 1 \times X 2-3.76667 \times X 2^{2}
\end{aligned}
$$

ANOVA revealed a significant antagonistic effect of $\mathrm{X}_{1}$ $(\mathrm{MM}$ to inclusion complex ratio, $p$-value $=0.0054)$ on

(7) $\mathrm{Y}_{1}$. The percent of carbopol $\left(\mathrm{X}_{2}\right)$ demonstrated a marked significant effect on all the studied variables. 

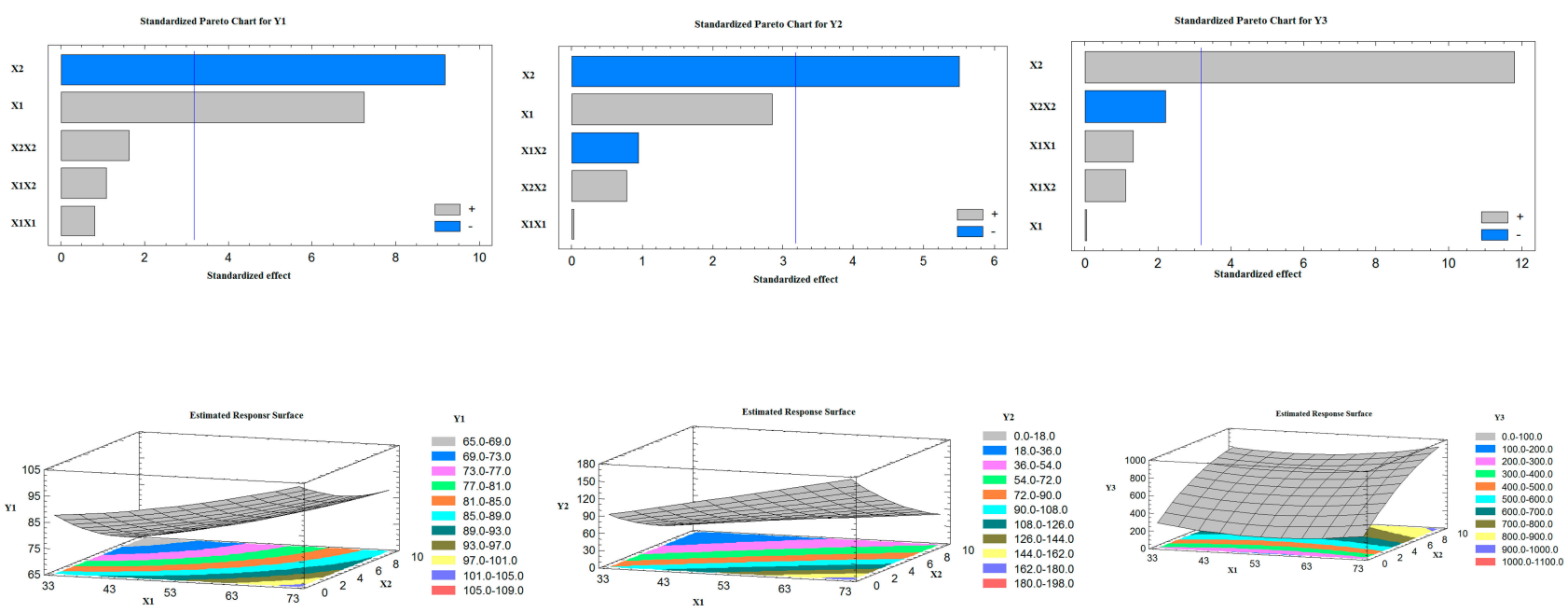

Figure 9 Standardized Pareto charts and estimated response surface plots for the effect of the studied factors on $Y_{1}-Y_{3}$

Abbreviations: $X_{1}$, mixed micelles nanoparticles to inclusion complex ratio; $X_{2}$, carbopol percent; $Y_{1}$, the cumulative percent of simvastatin release; $Y_{2}$, elongation percent; $Y_{3}$, mucoadhesive strength.

$\mathrm{X}_{2}$ was antagonistically affecting $\mathrm{Y}_{1}(P$-value $=0.0027)$ and $\mathrm{Y}_{2}(P$-value $=0.0119)$ while it showed an agonistic effect on $\mathrm{Y}_{3}(P$-value $=0.0013)$. The Pareto charts obtained, depicted in Figure 9, clearly confirm this finding. A vertical reference line at a $P$-value equals 0.05 is represented. An effect that exceeds this line is an indication of a significant effect. Moreover, to study the effect of changing the levels of $\mathrm{X}_{1}$ and $\mathrm{X}_{2}$ on $\mathrm{Y}_{1}, \mathrm{Y}_{2}$ and $Y_{3}$ the estimated response surface plots with contour below were generated and are graphically represented in Figure 9. In each plot, the studied variables $\left(\mathrm{X}_{1}\right.$ and $\left.\mathrm{X}_{2}\right)$ are located at two sides and are varied within a specified range. The responses $\left(\mathrm{Y}_{1}-\mathrm{Y}_{3}\right)$ are represented in the left side. The expected values for $\mathrm{Y}_{1}-\mathrm{Y}_{3}$ are demonstrated as a colored regions below (contour area). An explanation for the effect of the studied variables on each response was clarified in the above section.

\section{Preparation and Characterization of the Optimum SMV Buccal Film Formulation}

To develop an optimum SMV mucoadhesive buccal film formulation characterized by a maximum $Y_{1}, Y_{2}$ and $Y_{3}$, the optimum levels (desirability) for $\mathrm{X}_{1}$ and $\mathrm{X}_{2}$ were identified. Table 3 demonstrates the optimum desirability levels for the independent variables. The optimized formulation was prepared and characterized as previously described. The predicted, observed and residual values for the studied responses are depicted in Table 3.

The optimum formulation was also characterized for in vitro dissolution time and ex vivo drug release. The average dissolution time for this formulation was $8.9 \pm 2.5$

Table 3 The Optimum Levels and Desirability Values of Each Studied Factor and Multiple Response Optimization

\begin{tabular}{|c|c|c|c|c|c|c|}
\hline \multirow[t]{2}{*}{ Factors } & \multirow[t]{2}{*}{ Low } & \multirow[t]{2}{*}{ High } & \multicolumn{3}{|c|}{ Optimum Level for Each Response } & \multirow[t]{2}{*}{ Optimum Desirability Level } \\
\hline & & & $Y_{1}=99.68 \%$ & $Y_{2}=161.38 \%$ & $Y_{3}=826.27 \mathrm{~N}$ & \\
\hline $\mathbf{X}_{\mathbf{I}}$ (Ratio) & $1: 2$ & $2: 1$ & $2: 1$ & 2:1 & $2: 1$ & $2: 1$ \\
\hline $\mathbf{X}_{2}(\%)$ & 0 & 10 & 0 & 0 & 10 & 3.84 \\
\hline \multirow[t]{2}{*}{ Responses } & \multirow{2}{*}{\multicolumn{2}{|c|}{ Goal }} & \multicolumn{4}{|c|}{ Optimum Desirability } \\
\hline & & & \multicolumn{2}{|l|}{ Predicted Values } & Observed Values & Residual \\
\hline $\mathbf{Y}_{1}(\%)$ & \multicolumn{2}{|l|}{ Maximize } & \multicolumn{2}{|l|}{90.73} & 92.74 & \pm 2.01 \\
\hline $\mathbf{Y}_{2}(\%)$ & \multicolumn{2}{|l|}{ Maximize } & \multicolumn{2}{|l|}{106.18} & 110.54 & \pm 4.36 \\
\hline $\mathbf{Y}_{3}(\mathbf{N})$ & \multicolumn{2}{|l|}{ Maximize } & 553.09 & & $523.4 I$ & \pm 29.68 \\
\hline
\end{tabular}

Abbreviations: $X_{1}$, mixed micelle to inclusion complex ratio; $X_{2}$, percent of carbopol; $Y_{1}$, cumulative percent of drug released; $Y_{2}$, elongation percent; $Y_{3}$, mucoadhesive strength. 
Table 4 Permeation Parameters for the Release Data of SMV Mucoadhesive Buccal Films

\begin{tabular}{|l|l|l|l|}
\hline Run & $\begin{array}{l}\text { Jss } \\
\left(\mu \mathrm{g} / \mathrm{cm}^{\mathbf{2}} \mathbf{~ m i n}\right)\end{array}$ & $\begin{array}{l}\mathbf{P} \times \mathbf{I 0}^{-\mathbf{4}} \\
(\mathbf{c m} / \mathbf{m i n})\end{array}$ & $\begin{array}{l}\mathbf{D} \times 1 \mathbf{0}^{-4} \\
(\mathbf{c m} / \mathbf{m i n})\end{array}$ \\
\hline FI & 1.208 & 17.560 & 21.974 \\
F2 & 1.166 & 16.954 & 20.406 \\
F3 & 1.470 & 21.368 & 32.369 \\
F4 & 1.249 & 18.065 & 23.581 \\
F5 & 1.502 & 21.825 & 34.167 \\
F6 & 1.106 & 15.998 & 18.552 \\
F7 & 1.237 & 17.977 & 22.979 \\
F8 & 1.238 & 18.006 & 22.973 \\
F9 & 1.132 & 16.452 & 19.154 \\
Opt. Formulation & 1.704 & 24.159 & 42.638 \\
Pure Drug & 0.9324 & 13.552 & 12.904 \\
Formulation & & & \\
\hline
\end{tabular}

Abbreviations: Jss, steady state flux; P, permeability coefficient; D, diffusion coefficient.

minutes. Vila et al reported an in vitro dissolution time of $6.6 \pm 3.0$ minutes for pure drug-loaded pullan-based mucoadhesive buccal film. ${ }^{25}$ Our results are slightly higher than that reported by Vila et al due to the presence of SMV in the form of MM nanoparticles and inclusion complex. Results for the ex vivo permeation across the bovine buccal mucosal tissue indicated superiority of the optimized formulation loaded with MM nanoparticles and inclusion complex when compared to the corresponding film infused with pure drug (data not shown). The calculated results for the permeation parameters presented in Table 4 also confirmed this finding. Accordingly, the optimized SMV loaded buccal film is a promising drug delivery system that exhibits dual release mechanisms from the MM nanoparticles and inclusion complex drug carriers. The developed films are expected to enhance SMV bioavailability due to enhanced drug aqueous solubility, improved drug permeation and avoidance of the first-pass effect from the buccal route.

\section{Conclusions}

Complexation of SMV with HP $\beta$-CD was superior to all the studied polymers and resulted in enhancement of the drug aqueous solubility. Nano-sized SMV MM formulation was well developed and it showed spherical shape nanoparticles. Both carrier systems enhanced the drug permeation across OEC. The optimization technique was successfully implemented to develop mucoadhesive buccal films containing different ratios of both carriers and various concentration of carbopol. The technique was implemented to maximize the percent of drug release, the elongation percent and the mucoadhesive strength. Mucoadhesive buccal films loaded with SMV in the form of HP $\beta$-CD inclusion complex and MM nanoparticles are efficient drug delivery system with enhanced drug ex vivo permeation. It is expected that the prepared SMV loaded mucoadhesive buccal film formulation could enhance the drug bioavailability and so, it can be considered as an alternative to currently available marketed SMV oral tablets.

\section{Acknowledgment}

This project was funded by the Deanship of Scientific Research (DSR) at King Abdulaziz University, Jeddah, under grant no. (RG-16-166-40). The authors, therefore, acknowledge with thanks to DSR for technical and financial support.

\section{Disclosure}

The authors report no conflicts of interest in this work.

\section{References}

1. Kreatsoulas C, Anand SS. The impact of social determinants on cardiovascular disease. Can J Cardiol. 2010;26(Suppl C):8C-13C. doi:10.1016/s0828-282x(10)71075-8

2. Moghadasian MH. Clinical pharmacology of 3-hydroxy-3-methylglutaryl coenzyme a reductase inhibitors. Life Sci. 1999;65(13):13 29-1337. doi:10.1016/S0024-3205(99)00199-X

3. Parhi R, Suresh P. Formulation optimization and characterization of transdermal film of simvastatin by response surface methodology. Mater Sci Eng C. 2016;58:331-341. doi:10.1016/j.msec.2015.08.056

4. Kong R, Zhu X, Meteleva ES, et al. Enhanced solubility and bioavailability of simvastatin by mechanochemically obtained complexes. Int J Pharm. 2017;534(1-2):108-118. doi:10.1016/j.ijpharm.2017.10. 011

5. Ahmed OAA, Hosny KM, Al-Sawahli MM, Fahmy UA. Optimization of caseinate-coated simvastatin-zein nanoparticles: improved bioavailability and modified release characteristics. Drug Des Devel Ther. 2015;9:655-662. doi:10.2147/DDDT.S76194

6. Pandya VM, Patel JK, Patel DJ. Formulation and optimization of nanosuspensions for enhancing simvastatin dissolution using central composite design. Dissolut Technol. 2011;18(3):40-45. doi:10.14227/ DT180311P40

7. Ahmed TA, Badr-Eldin SM, Ahmed OAA, Aldawsari H. Intranasal optimized solid lipid nanoparticles loaded in situ gel for enhancing trans-mucosal delivery of simvastatin. J Drug Deliv Sci Technol. 2018;48(July):499-508. doi:10.1016/J.JDDST.2018.10.027

8. Kumar S, Shen J, Burgess DJ. Nano-amorphous spray dried powder to improve oral bioavailability of itraconazole. J Control Release. 2014;192:95-102. doi:10.1016/j.jconrel.2014.06.059

9. Krishnaiah Y. Pharmaceutical technologies for enhancing oral bioavailability of poorly soluble drugs. J Bioequiv Availab. 2010;02 (02):28-36. doi:10.4172/jbb.1000027

10. Vimalson CD, Parimalakrishnan S, Jeganathan NS, Anbazhagan S. Techniques to enhance solubility of hydrophobic drugs: an overview. Asian J Pharm. 2016;10(2):S67-S75. doi:10.22377/ajp.v10i2.625 
11. Ahmed TA, El-Say KM. Transdermal film-loaded finasteride microplates to enhance drug skin permeation: two-step optimization study. Eur J Pharm Sci. 2016;88:246-256. doi:10.1016/j.ejps.2016.03.015

12. Ahmed TA. Preparation of finasteride capsules-loaded drug nanoparticles: formulation, optimization, in vitro, and pharmacokinetic evaluation. Int J Nanomedicine. 2016;11:515-527. doi:10.2147/IJN.S98080

13. Alshahrani SM, Lu W, Park J-B, et al. Stability-enhanced hot-melt extruded amorphous solid dispersions via combinations of soluplus ${ }^{\circledR}$ and HPMCAS-HF. AAPS PharmSciTech. 2015;16(4):824-834. doi:10.1208/s12249-014-0269-6

14. Ahmed TA. Formulation and clinical investigation of optimized vinpocetine lyoplant-tabs: new strategy in development of buccal solid dosage form. Drug Des Devel Ther. 2019;13:205-220. doi:10.2147/ DDDT.S189105

15. Pande VV, Abhale VN, Möschwitzer JP. Nanocrystal technology: a particle engineering formulation strategy for the poorly water soluble drugs. Int J Pharm. 2013;453(1):126-141. doi:10.1016/j. ijpharm.2013.01.019

16. Fahr A, Liu X. Drug delivery strategies for poorly water-soluble drugs. Expert Opin Drug Deliv. 2007;4(4):403-416. doi:10.1517/ 17425247.4.4.403

17. Zhang D, Lee Y-C, Shabani Z, et al. Processing impact on performance of solid dispersions. Pharmaceutics. 2018;10(3):142. doi:10.3390/pharmaceutics10030142

18. Savjani KT, Gajjar AK, Savjani JK. Drug solubility: importance and enhancement techniques. ISRN Pharm. 2012;2012:1-10. doi:10.54 02/2012/195727

19. Bauduin P, Renoncourt A, Kopf A, Touraud D, Kunz W. Unified concept of solubilization in water by hydrotropes and cosolvents. Langmuir. 2005;21(15):6769-6775. doi:10.1021/LA050554L

20. Makar RR, Latif R, Hosni EA, El Gazayerly ON. Optimization for glimepiride dissolution enhancement utilizing different carriers and techniques. J Pharm Investig. 2013;43(2):115-131. doi:10.1007/s40 005-013-0061-8

21. Badr-Eldin SM, Ahmed TA, Ismail HR. Aripiprazole-cyclodextrin binary systems for dissolution enhancement: effect of preparation technique, cyclodextrin type and molar ratio. Iran J Basic Med Sci. 2013;16(12):1223-1231.

22. Carrier RL, Miller LA, Ahmed I. The utility of cyclodextrins for enhancing oral bioavailability. J Control Release. 2007;123(2):78-99. doi:10.1016/j.jconrel.2007.07.018

23. Rangel-Yagui CO, Pessoa A, Tavares LC. Micellar solubilization of drugs. J Pharm Pharm Sci. 2005;8(2):147-165.:

24. Liu T, Wan X, Luo Z, et al. A donepezil/cyclodextrin complexation orodispersible film: effect of cyclodextrin on taste-masking based on dynamic process and in vivo drug absorption. Asian J Pharm Sci. 2019;14(2):183-192. doi:10.1016/J.AJPS.2018.05.001

25. Vila MMDC, Tardelli ER, Chaud MV, Tubino M, Balcão VM. Development of a buccal mucoadhesive film for fast dissolution: mathematical rationale, production and physicochemical characterization. Drug Deliv. 2014;21(7):530-539. doi:10.3109/107 17544.2013.851301

26. Kharenko EA, Larionova NI, Demina NB. Mucoadhesive drug delivery systems (Review). Pharm Chem J. 2009;43(4):200-208. doi:10. 1007/s11094-009-0271-6

27. Carvalho FC, Bruschi ML, Evangelista RC, Gremião MPD. Mucoadhesive drug delivery systems. Braz J Pharm Sci. 2010;46 (1):1-17. doi:10.3109/03639045.2011.623355

28. Ammar HO, Ghorab MM, Mahmoud AA, Shahin HI. Design and in vitro/in vivo evaluation of ultra-thin mucoadhesive buccal film containing fluticasone propionate. AAPS PharmSciTech. 2017;18 (1):93-103. doi:10.1208/s12249-016-0496-0

29. Mansuri S, Kesharwani P, Jain K, Tekade RK, Jain NK Mucoadhesion: a promising approach in drug delivery system. React Funct Polym. 2016;100:151-172. doi:10.1016/j.reactfunctpolym.2016. 01.011
30. Seo S, Lee C-S, Jung Y-S, Na K. Thermo-sensitivity and triggered drug release of polysaccharide nanogels derived from pullulan-g-poly (1-lactide) copolymers. Carbohydr Polym. 2012;87(2):1105-1111. doi:10.1016/J.CARBPOL.2011.08.061

31. Higuchi T, Connors K. Phase solubility techniques. Adv Anal Chem Instrum. 1965;4:117-212.

32. Lv Q, Shen C, Li X, et al. Mucoadhesive buccal films containing phospholipid-bile salts-mixed micelles as an effective carrier for Cucurbitacin B delivery. Drug Deliv. 2015;22(3):351-358. doi:10.3109/10717544.2013.876459

33. El-Say KM, Ahmed TA, Badr-Eldin SM, Fahmy U, Hibah A, Ahmed OAA. Enhanced permeation parameters of optimized nanostructured simvastatin transdermal films: ex vivo and in vivo evaluation. Pharm Dev Technol. 2015;20(8):919-926. doi:10.3109/ 10837450.2014.938859

34. Dixit RP, Puthli SP. Oral strip technology: overview and future potential. J Control Release. 2009;139(2):94-107. doi:10.1016/j. jconrel.2009.06.014

35. Ahmed TA, El-Say KM. Development of alginate-reinforced chitosan nanoparticles utilizing $\mathrm{W} / \mathrm{O}$ nanoemulsification/internal crosslinking technique for transdermal delivery of rabeprazole. Life Sci. 2014;110 (1):35-43. doi:10.1016/j.1fs.2014.06.019

36. Ahmed TA, Alay AMS, Okbazghi SZ, Alhakamy NA. Two-step optimization to develop a transdermal film loaded with dapoxetine nanoparticles: a promising technique to improve drug skin permeation. Dose-Response. 2020;(April-June):1-15. doi:10.1177/1559325820923859

37. Yu T, Andrews GP, Jones DS. Mucoadhesion and characterization of mucoadhesive properties. Mucosal Delivery of Biopharmaceuticals. Boston, MA: Springer US; 2014:35-58. doi:10.1007/978-1-4614-95246 -2

38. Nair AB, Kumria R, Harsha S, Attimarad M, Al-Dhubiab BE, Alhaider IA. In vitro techniques to evaluate buccal films. J Control Release. 2013;166(1):10-21. doi:10.1016/j.jconrel.2012.11.019

39. García MC, Aldana AA, Tártara LI, et al. Bioadhesive and biocompatible films as wound dressing materials based on a novel dendronized chitosan loaded with ciprofloxacin. Carbohydr Polym. 2017;175:75-86. doi:10.1016/j.carbpol.2017.07.053

40. Yu T, Andrews G, Jones D. Mucoadhesion and characterization of mucoadhesive properties. Mucosal Delivery of Biopharmaceuticals. Belfast; 2014:35-58. doi:10.1007/978-1-4614-9524-6.

41. Thongborisute J, Takeuchi H. Evaluation of mucoadhesiveness of polymers by BIACORE method and mucin-particle method. Int J Pharm. 2008;354(1-2):204-209. doi:10.1016/j.ijpharm.2007.12.001

42. Tiwari R, Pathak K. Nanostructured lipid carrier versus solid lipid nanoparticles of simvastatin: comparative analysis of characteristics, pharmacokinetics and tissue uptake. Int J Pharm. 2011;415(12):232-243. doi:10.1016/j.ijpharm.2011.05.044

43. Zhang L, Liu M, Lu C, et al. The hydroxypropyl- $\beta$-cyclodextrin complexation of toltrazuril for enhancing bioavailability. Drug Des Devel Ther. 2018;12:583-589. doi:10.2147/DDDT.S157611

44. Parmar KR, Patel KA, Shah SR, Sheth NR. Inclusion complexes of lamotrigine and hydroxy propyl $\beta$-cyclodextrin: solid state characterization and dissolution studies. J Incl Phenom Macrocycl Chem. 2009;65(3):263-268. doi:10.1007/s10847-009-9577-y

45. Mura P, Corti G, Cirri M, Maestrelli F, Mennini N, Bragagni M. Development of mucoadhesive films for buccal administration of flufenamic acid: effect of cyclodextrin complexation. J Pharm Sci. 2010;99(7):3019-3029. doi:10.1002/jps.22068

46. Kumria R, Harsha S, Attimarad M, Al-Dhubiab BE, Nair AB. Formulation and evaluation of nano based drug delivery system for the buccal delivery of acyclovir. Colloids Surf B Biointerfaces. 2015;136:878-884. doi:10.1016/j.colsurfb.2015.10.045

47. Kumar P, Mohan C, Srinivasan MK, Shankar U, Gulati M. Physiochemical characterization and release rate studies of solid dispersions of ketoconazole with pluronic F127 and PVP K-30. Iran J Pharm Res. 2011;10(4):685-694. 
48. Wook Jun S, Kim M-S, Kim J-S, et al. Preparation and characterization of simvastatin/hydroxypropyl-b-cyclodextrin inclusion complex using supercritical antisolvent (SAS) process. Eur $J$ Pharm Biopharm. 2007;66(3):413-421. doi:10.1016/j.ejpb.2006.11.013

49. Shulman M, Cohen M, Soto-Gutierrez A, et al. Enhancement of naringenin bioavailability by complexation with hydroxypropoyl- $\beta$ cyclodextrin. PLoS One. 2011;6(4):e18033. doi:10.1371/journal. pone.0018033

50. Doile MM, Fortunato KA, Schmücker IC, Schucko SK, Silva MAS, Rodrigues PO. Physicochemical properties and dissolution studies of dexamethasone acetate- $\beta$-cyclodextrin inclusion complexes produced by different methods. AAPS PharmSciTech. 2008;9(1):314-321. doi:10.1208/s12249-008-9042-z

51. Lodagekar A, Borkar RM, Thatikonda S, et al. Formulation and evaluation of cyclodextrin complexes for improved anticancer activity of repurposed drug: niclosamide. Carbohydr Polym. 2019;2 12:252-259. doi:10.1016/j.carbpol.2019.02.041

52. Furuishi T, Sekino K, Gunji M, et al. Effect of sulfobutyl ether- $\beta$ cyclodextrin and propylene glycol alginate on the solubility of clozapine. Pharm Dev Technol. 2019;24(4):479-486. doi:10.1080/ 10837450.2018.1514521

53. Ahmed TA, Suhail MAA, Hosny KM, Abd-Allah FI. Clinical pharmacokinetic study for the effect of glimepiride matrix tablets developed by quality by design concept. Drug Dev Ind Pharm. 2018;44 (1):66-81. doi:10.1080/03639045.2017.1371740

54. Ol'khovich MV, Sharapova AV, Perlovich GL, Skachilova SY, Zheltukhin NK. Inclusion complex of antiasthmatic compound with 2-hydroxypropyl- $\beta$-cyclodextrin: preparation and physicochemical properties. J Mol Liq. 2017;237:185-192. doi:10.1016/j.molliq.20 17.04 .098

55. Choi SG, Lee S-E, Kang B-S, Ng CL, Davaa E, Park J-S. Thermosensitive and mucoadhesive sol-gel composites of paclitaxel/dimethyl- $\beta$-cyclodextrin for buccal delivery. Xu B ed. PLoS One. 2014;9(10):e109090. doi:10.1371/journal.pone.0109090

56. Singh R, Bharti N, Madan J, Hiremath SN. Characterization of cyclodextrin inclusion complexes - a review. J Pharm Sci Technol. 2010;2(3):171-183.

57. Singh H, Philip B, Pathak K. Preparation, characterization and pharmacodynamic evaluation of fused dispersions of simvastatin using PEO-PPO block copolymer. Iran J Pharm Res. 2012;11(2):433-445.

58. Onyeji CO, Igbinoba SI, Oladimeji F, Soyinka J. Physicochemical characterization and dissolution properties of binary systems of pyrimethamine and 2-. Afr J Biotechnol. 2009;8(8):1651-1659.

59. Duan Y, Wang J, Yang X, Du H, Xi Y, Zhai G. Curcumin-loaded mixed micelles: preparation, optimization, physicochemical properties and cytotoxicity in vitro. Drug Deliv. 2015;22(1):50-57. doi:10. 3109/10717544.2013.873501

60. Dangi JS, Vyas SP, Dixit VK. The role of mixed micelles in drug delivery. I. solubilization. Drug Dev Ind Pharm. 1998;24(7):681-684. doi:10.3109/03639049809082372
61. Mazer NA, Benedek GB, Carey MC. Quasielastic light-scattering studies of aqueous biliary lipid systems. Mixed micelle formation in bile salt-lecithin solutions. Biochemistry. 1980;19(4):601-615. doi:10. 1021/bi00545a001

62. Zhao L, Du J, Duan Y, et al. Curcumin loaded mixed micelles composed of pluronic P123 and F68: preparation, optimization and in vitro characterization. Colloids Surf B Biointerfaces. 2012;97: 101-108. doi:10.1016/J.COLSURFB.2012.04.017

63. Schott H. Surfactant systems: their chemistry, pharmacy and biology. Attwood D, Florence AT (Eds). J Pharm Sci. 1985;74(10):11 40-1141. doi:10.1002/JPS.2600741040

64. Jiang T, Han N, Zhao B, Xie Y, Wang S. Enhanced dissolution rate and oral bioavailability of simvastatin nanocrystal prepared by sonoprecipitation. Drug Dev Ind Pharm. 2012;38(10):1230-1239. doi:10.3109/03639045.2011.645830

65. Karki S, Kim H, Na SJ, Shin D, Jo K, Lee J. Thin films as an emerging platform for drug delivery. Asian J Pharm Sci. 2016;11 (5):559-574. doi:10.1016/j.ajps.2016.05.004

66. Perumal VA, Lutchman D, Mackraj I, Govender T. Formulation of monolayered films with drug and polymers of opposing solubilities. Int J Pharm. 2008;358(1-2):184-191. doi:10.1016/j.ijpharm.2008. 03.005

67. Alopaeus JF, Hellfritzsch M, Gutowski T, et al. Mucoadhesive buccal films based on a graft co-polymer - a mucin-retentive hydrogel scaffold. Eur J Pharm Sci. 2020:142. doi:10.1016/j.ejps.2019.105 142.

68. Hoffmann A, Daniels R. A novel test system for the evaluation of oral mucoadhesion of fast disintegrating tablets. Int J Pharm. 2018;551(1-2):141-147. doi:10.1016/j.ijpharm.2018.09.001

69. Sudhakar Y, Kuotsu K, Bandyopadhyay AK. Buccal bioadhesive drug delivery - a promising option for orally less efficient drugs. $J$ Control Release. 2006;114(1):15-40. doi:10.1016/j.jconrel.2006. 04.012

70. Perez-vilar J, Hill RL. The structure and assembly of secreted mucins. J Biol Chem. 1999;274(45):31751-31755. doi:10.1074/ jbc.274.45.31751

71. Onnainty R, Onida B, Páez P, Longhi M, Barresi A, Granero G. Targeted chitosan-based bionanocomposites for controlled oral mucosal delivery of chlorhexidine. Int J Pharm. 2016;509(1-2):408-418. doi:10.1016/j.ijpharm.2016.06.011

72. da Silva JB, Ferreira SB de S, Reis AV, Cook MT, Bruschi ML. Assessing mucoadhesion in polymer gels: the effect of method type and instrument variables. Polymers (Basel). 2018;10(3). doi:10.3390/ polym 10030254

73. Peppas NA, Huang Y. Nanoscale technology of mucoadhesive interactions. Adv Drug Deliv Rev. 2004;56(11):1675-1687. doi:10.10 16/j.addr.2004.03.001
International Journal of Nanomedicine

\section{Publish your work in this journal}

The International Journal of Nanomedicine is an international, peerreviewed journal focusing on the application of nanotechnology in diagnostics, therapeutics, and drug delivery systems throughout the biomedical field. This journal is indexed on PubMed Central, MedLine, CAS, SciSearch ${ }^{\mathbb{R}}$, Current Contents ${ }^{\mathbb{R}} /$ Clinical Medicine, $^{2}$
Journal Citation Reports/Science Edition, EMBase, Scopus and the Elsevier Bibliographic databases. The manuscript management system is completely online and includes a very quick and fair peer-review system, which is all easy to use. Visit http://www.dovepress.com/ testimonials.php to read real quotes from published authors. 